\title{
Contenido y alcance de la reforma energética ${ }^{1}$ Content and scope of the energy reform
}

\author{
Resumen
}

Journal of Economic Literature (JEL):

E62, L71, Q4, Q48

Palabras clave:

Política fiscal

Hidrocarburos

Energía

Política gubernamental

Keywords:

Fiscal Policy

Hidrocarbon fuels

Energy

Gobernment Policy
Analiza el funcionamiento estructural del sistema energético mexicano y sus vínculos con el crecimiento, la estabilidad y el desarrollo, así como las motivaciones que dieron lugar a la reforma constitucional de 2013. Se examina el impacto de la reforma en Pemex y las repercusiones de distribuir con actores privados que sobrelleva la apertura mercantil, derechos y obligaciones del Estado en la explotación y aprovechamiento de los hidrocarburos propiedad de la Nación. Se advierte que la reforma agrava la creciente disfuncionalidad estructural, pues no ofrece salida a la concentración extrema del sistema energético; prioriza las actividades primarias y margina las de transformación industrial; refuerza el sesgo exportador de crudo e importador de derivados del petróleo; agrava la carga fiscal y la quiebra financiera latente de Pemex; y cede al mercado la inserción del sistema energético nacional en la transición energética global.

\section{Abstract}

The Mexican energy system is analysed looking at its links with the long-term growth, stability and development of the country's economy. The political, economic and financial factors behind the 2013 Constitutional amendment on energy are also examined. Looks at the impact of the oil market opening on Pemex and the implications of sharing with private actorsthe rights and obligations of the State in the exploitation and utilization of hydrocarbons property of the Nation. Among the main conclusions, underlines the following: the reform worsens the growing structural dysfunction of Mexican energy sector, aggravating its extreme concentration on fossil fuels; prioritize the primary activities and marginalizes those related to industrial hydrocarbon processing; it reinforces already existing bias as exporter of crude oil and importer of petroleum products; it increases the fiscal burden and the latent financial bankruptcy of Pemex, and leaves to

1 El Grupo de Energía del PUED, agradece a ECONOMíAunam su interés de publicar una versión editada de este capítulo del Informe del PUED sobre Desarrollo 2015. Agradece también los comentarios y sugerencias de Víctor Rodríguez y Fluvio Ruiz. 
the market the pace and modalities of inclusion of the national energy system into the global energy transition.

\section{Introducción}

La reforma en materia de energía, instrumentada a partir de las enmiendas constitucionales de diciembre de 2013, modifica el funcionamiento del sistema energético nacional y sus vínculos con el crecimiento, la estabilidad de la economía y las opciones de desarrollo. En el primer apartado se analizan las características del sistema energético mexicano en referencia a las transformaciones que se pretende alcanzar con la reforma. A partir de ello, se profundiza en la reforma de Petróleos Mexicanos (Pemex), el actor de mayor importancia en el sector mexicano de energía, así como algunas de sus derivaciones para el resto del sistema energético nacional. Por último, se analiza la distribución de los recursos de hidrocarburos entre la ahora empresa productiva del Estado (EPE) y los nuevos actores resultantes de la apertura en el subsector de hidrocarburos. Se presenta una primera aproximación a la viabilidad de alcanzar los beneficios esperados y a otras implicaciones previsibles en las articulaciones del sector de la energía, principalmente respecto de las finanzas públicas y el patrimonio nacional. Se enfatiza que una cabal comprensión de estos elementos es fundamental para la formulación de una política energética para el desarrollo, que tome en cuenta la nueva configuración del sector mexicano de energía.

\section{Características estructurales del sistema energético nacional}

El funcionamiento del sistema energético nacional se gestó desde las décadas de 1970 y 1980. En ese marco jurídico e institucional, correspondió al Estado, en exclusividad, el manejo de las actividades centrales de los subsectores petrolero y eléctrico, en general, en un ambiente de acelerado dinamismo del sector, y en particular, de intensa expansión en la capacidad de extracción de hidrocarburos. Así, las reservas petroleras registradas en 1983 han sido las más altas de la historia. A partir de ese año y hasta la actualidad, se registra un descenso constante. Los descubrimientos han sido insuficientes para restituir los volúmenes extraídos. Al cierre de 2014 las denominadas reservas 3P (probadas, posibles y probables) equivalieron a alrededor de la mitad del máximo de 1983: 37404 y 72500 millones de barriles de petróleo crudo equivalente (mmbpe) (gráfica 1).

La capacidad instalada de transformación industrial de los hidrocarburos también experimentó un ensanchamiento drástico antes de 1982, que culminó en ese año con niveles sin precedente, cuya dimensión y perfil define, en gran parte, la situación actual de dicha capacidad. El Sistema Nacional de Refinación llegó a contar en ese año con siete refinerías y capacidad de proceso de crudo de 1.5 millones de barriles diarios. El Sistema actual se integra por seis de esas siete refinerías, con la misma capacidad de proceso. 


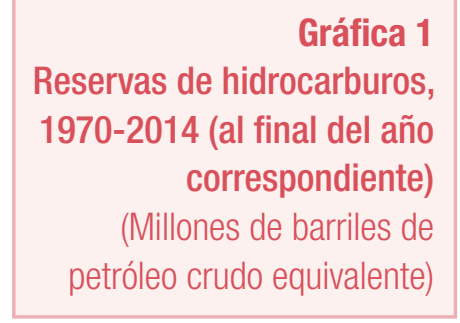

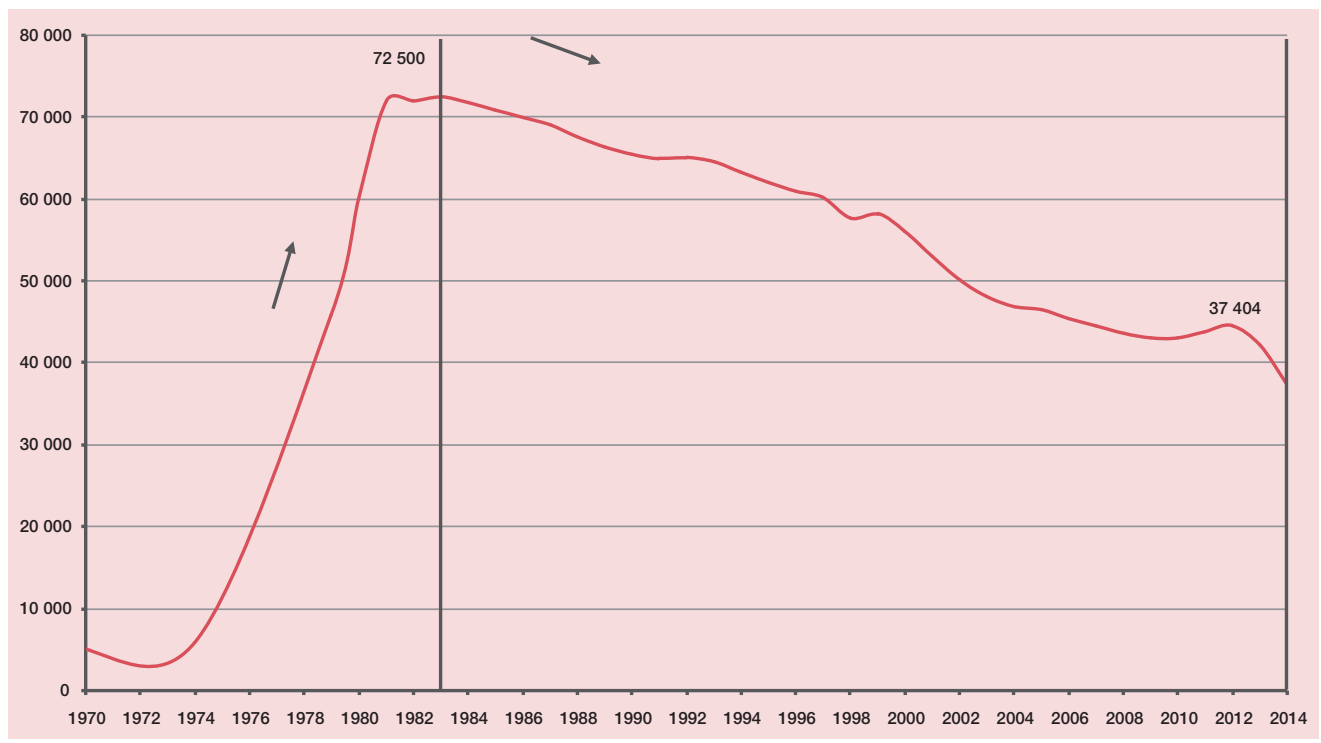

Fuente: elaboración propia con información de Secretaría de Energía: Sistema de Información Energética y Petróleos Mexicanos: Anuarios Estadísticos.

El sistema energético nacional que opera desde principios de la década de 1980, reviste características estructurales que facilitaron su funcionamiento por algún tiempo. Pero ya en 2014 muestra síntomas evidentes de incapacidad para seguir operando con el dinamismo del pasado. La reforma energética fue la fórmula imaginada por el gobierno para responder a la creciente disfuncionalidad del sistema energético nacional. Entre las características de dicho sistema que resultaba necesario reformar destacan la concentración inflexible de las fuentes de energía primaria en los hidrocarburos; la insuficiencia dinámica de la oferta nacional de extracción y de transformación industrial de éstos, y la extrema vulnerabilidad que ocasiona el cumplimiento de objetivos fiscales y de exportación de hidrocarburos, establecidos sin correspondencia con las posibilidades que ofrece la oferta de éstos.

\section{Concentración extremada en los hidrocarburos}

El patrón energético nacional se caracteriza por una acentuada dependencia de los hidrocarburos, de modo tal que la evolución de la oferta y demanda de éstos no sólo determina el comportamiento del sector energético en su conjunto, sino también buena parte de las transacciones externas, el mercado de divisas y, en especial, las finanzas públicas. La oferta primaria de energía del país proveniente de los hidrocarburos fue $82 \%$ en 2013 , cifra muy superior a la de otras fuentes de suministro energético (véase cuadro 1). 


\begin{tabular}{|c|c|c|c|c|c|c|c|c|c|c|}
\hline \multicolumn{11}{|c|}{$\begin{array}{l}\text { Oferta de energía primaria, años seleccionados 1965-2013 } \\
\text { (Estructura porcentual) }\end{array}$} \\
\hline \multirow[b]{2}{*}{ Año } & \multirow[t]{2}{*}{ Total } & \multirow[t]{2}{*}{ Hidrocarburos } & \multirow[t]{2}{*}{ Carbón } & \multirow[t]{2}{*}{ Nuclear } & \multicolumn{6}{|c|}{ Renovable } \\
\hline & & & & & Total & Leña & $\begin{array}{l}\text { Bagazo } \\
\text { de caña }\end{array}$ & Geotérmica & Hidráulica & $\begin{array}{l}\text { Otras } \\
(1)\end{array}$ \\
\hline 1965 & 100.0 & 78.7 & 2.0 & 0 & 19.3 & 12.9 & 3.4 & 0 & 3.0 & 0 \\
\hline 1970 & 100.0 & 79.9 & 2.4 & 0 & 17.6 & 10.7 & 3.1 & 0 & 3.8 & 0 \\
\hline 1975 & 100.0 & 81.8 & 3.5 & 0 & 14.7 & 8.8 & 2.8 & 0.3 & 2.9 & 0 \\
\hline 1980 & 100.0 & 88.6 & 2.3 & 0 & 9.1 & 5.3 & 1.9 & 0.3 & 1.7 & 0 \\
\hline 1982 & 100.0 & 89.2 & 2.2 & 0 & 8.6 & 4.8 & 1.6 & 0.3 & 1.9 & 0 \\
\hline 1985 & 100.0 & 88.1 & 2.7 & 0 & 9.2 & 4.8 & 1.8 & 0.4 & 2.2 & 0 \\
\hline 1990 & 100.0 & 86.3 & 2.9 & 0.6 & 10.2 & 5.6 & 1.6 & 1.1 & 1.8 & 0.01 \\
\hline 1995 & 100.0 & 84.3 & 4.0 & 1.8 & 10.0 & 5.3 & 1.7 & 1.1 & 1.9 & 0.02 \\
\hline 2000 & 100.0 & 83.5 & 4.3 & 1.5 & 10.6 & 4.8 & 1.5 & 2.3 & 2.0 & 0.03 \\
\hline 2005 & 100.0 & 80.6 & 9.1 & 1.6 & 8.8 & 3.7 & 1.4 & 2.3 & 1.4 & 0.04 \\
\hline 2010 & 100.0 & 80.1 & 10.0 & 0.9 & 9.0 & 3.6 & 1.2 & 2.1 & 1.9 & 0.2 \\
\hline 2013 & 100.0 & 81.8 & 7.7 & 1.7 & 8.8 & 3.5 & 1.7 & 1.8 & 1.4 & 0.3 \\
\hline
\end{tabular}

Fuente: elaboración propia con información de Secretaría de Energía: Sistema de Información Energética.Nota. La suma de los parciales pudiese no coincidir con el total debido al redondeo de las cifras.

(1) Incluye: biogás, eólica y solar.

El peso específico de los hidrocarburos en la oferta de energía primaria, a pesar del descenso observado desde 1982, en que alcanzó un máximo histórico de $89 \%$, mantiene un nivel dominante (82\%), que contrasta con el promedio mundial de $53 \%$, observado en 2012 y con $62 \%$ registrado por los países de la OCDE. En el caso de la generación de electricidad la dependencia de los hidrocarburos es análoga: $72 \%$ de la generación utiliza hidrocarburos como combustible, mientras el promedio mundial en 2012 fue de 28\% (cuadro 2). En dicho año, el país se situó en el cuarto y quinto lugar en la generación mundial de electricidad a base de petróleo y gas natural, respectivamente, en tanto que fue marginal su participación en las demás fuentes de energía, con la excepción de la geotermia.

\section{Cuadro 2}

Generación de electricidad por fuente de energía, años seleccionados 1995-2014 (Estructura porcentual)

\begin{tabular}{|c|c|c|c|c|c|}
\hline Año & Total & Hidrocarburos & Carbón & Renovable & Nuclear \\
\hline 1995 & 100.0 & 60.6 & 10.2 & 23.3 & 5.9 \\
\hline 2000 & 100.0 & 65.8 & 9.7 & 20.2 & 4.3 \\
\hline 2005 & 100.0 & 70.5 & 8.5 & 16.1 & 5.0 \\
\hline 2010 & 100.0 & 72.7 & 6.8 & 18.0 & 2.4 \\
\hline 2014 & 100.0 & 71.6 & 6.8 & 17.9 & 3.7 \\
\hline
\end{tabular}

Fuente: elaboración propia con información de Secretaría de Energía: Sistema de Información Energética. Nota 1. La suma de los parciales pudiese no coincidir con el total debido al redondeo de las cifras. Nota 2. No incluye cogeneración ni autoabastecimiento de energía eléctrica, e incluye la energía neta entregada a la red por los Productores Externos de Energía. 


\section{Insuficiencia dinámica}

\section{de la oferta nacional de hidrocarburos}

A la dependencia crónica de los hidrocarburos se suma -desde principios de la década de 1980-, una evolución relativamente estable y rígida de la oferta nacional de los mismos, tanto en su magnitud global como en la estructura de productos transformados que se colocan en los mercados nacional y externo. Para 1982 la extracción de hidrocarburos del país equivalió a cuatro y media veces el monto alcanzado en la década previa. A partir de entonces, durante 33 años, la extracción se ha mantenido dentro de una banda, en torno al promedio anual de 1399 millones de barriles, con límites no inferior a $12 \%$ ni superior a $17 \%$ de la media (gráfica 2 y cuadro 3 ).

\section{Gráfica 2}

Extracción anual de hidrocarburos, 1938-2015

(Millones de barriles de petróleo crudo equivalente

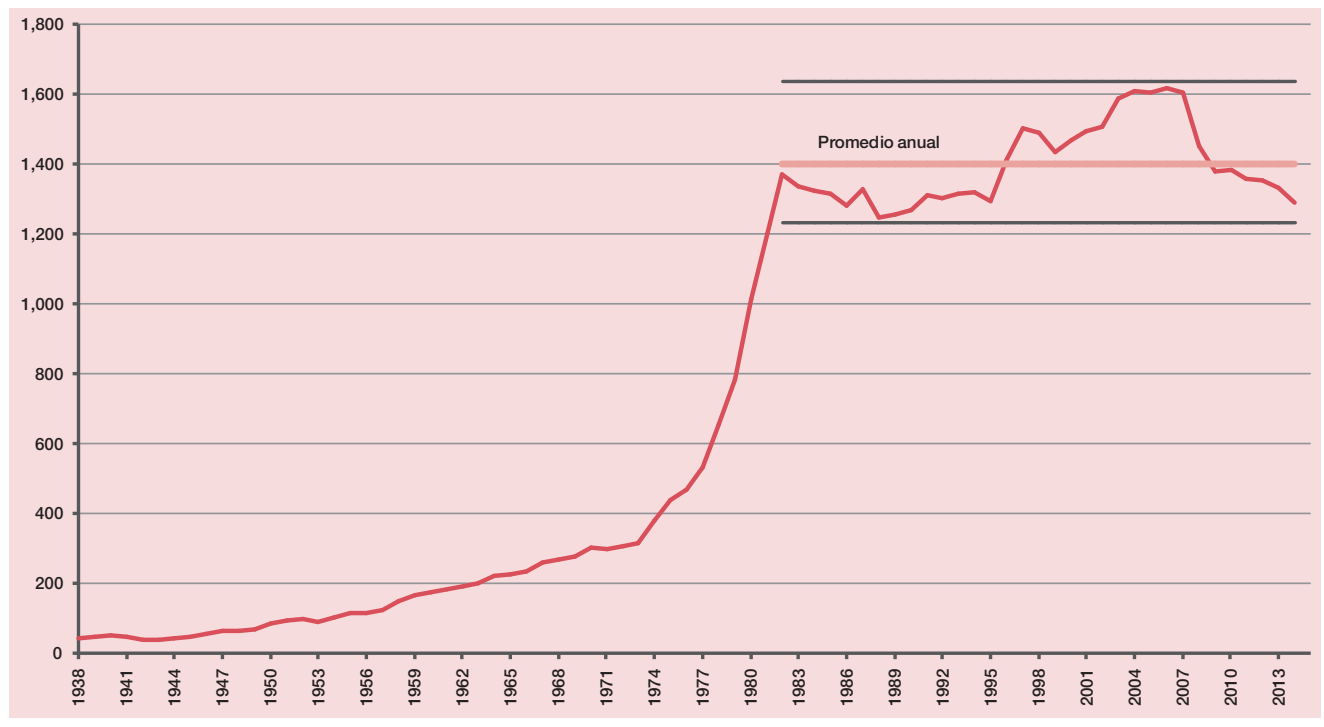

Fuente: elaboración propia con información de Petróleos Mexicanos: Anuarios Estadísticos e Informes Anuales). 
Cuadro 3

Extracción de hidrocarburos, años seleccionados 1938-2015

(Millones de barriles de petróleo crudo equivalente)

\begin{tabular}{|c|c|c|c|}
\hline Año & Total & Petróleo crudo & Gas natural (1) \\
\hline 1938 & 44 & 38 & 6 \\
\hline 1940 & 51 & 44 & 7 \\
\hline 1945 & 49 & 44 & 5 \\
\hline 1950 & 86 & 72 & 14 \\
\hline 1955 & 115 & 89 & 26 \\
\hline 1960 & 174 & 99 & 75 \\
\hline 1965 & 226 & 118 & 108 \\
\hline 1970 & 304 & 157 & 147 \\
\hline 1975 & 439 & 262 & 177 \\
\hline 1980 & 1015 & 709 & 306 \\
\hline 1981 & 1199 & 844 & 355 \\
\hline 1982 & 1372 & 1003 & 369 \\
\hline 1983 & 1338 & 981 & 357 \\
\hline 1984 & 1325 & 1024 & 301 \\
\hline 1985 & 1317 & 987 & 330 \\
\hline 1986 & 1283 & 913 & 370 \\
\hline 1987 & 1329 & 955 & 374 \\
\hline 1988 & 1248 & 945 & 303 \\
\hline 1989 & 1258 & 917 & 341 \\
\hline 1990 & 1268 & 930 & 338 \\
\hline 1991 & 1310 & 977 & 333 \\
\hline 1992 & 1304 & 974 & 330 \\
\hline 1993 & 1316 & 976 & 340 \\
\hline 1994 & 1320 & 980 & 340 \\
\hline 1995 & 1293 & 955 & 338 \\
\hline 1996 & 1413 & 1043 & 370 \\
\hline 1997 & 1504 & 1103 & 401 \\
\hline 1998 & 1490 & 1121 & 369 \\
\hline 1999 & 1434 & 1061 & 373 \\
\hline 2000 & 1469 & 1099 & 369 \\
\hline 2001 & 1494 & 1141 & 352 \\
\hline 2002 & 1508 & 1160 & 348 \\
\hline 2003 & 1587 & 1230 & 357 \\
\hline 2004 & 1611 & 1235 & 376 \\
\hline 2005 & 1604 & 1217 & 388 \\
\hline 2006 & 1618 & 1188 & 430 \\
\hline 2007 & 1603 & 1123 & 481 \\
\hline 2008 & 1451 & 1019 & 432 \\
\hline 2009 & 1378 & 949 & 429 \\
\hline 2010 & 1385 & 941 & 444 \\
\hline 2011 & 1359 & 932 & 427 \\
\hline 2012 & 1353 & 930 & 423 \\
\hline 2013 & 1333 & 921 & 413 \\
\hline 2014 & 1291 & 887 & 404 \\
\hline
\end{tabular}

Fuente: elaboración propia con información de Petróleos Mexicanos: Anuarios Estadísticos e Informes Anuales. Nota. Para el periodo 1938-1988 los condensados recuperados en fase líquida se incluyen en petróleo crudo, mientras que para el periodo 1989-2014 son incluidos en gas natural y líquidos del gas. (1) Incluye líquidos del gas 
En los últimos dos años se ha vuelto más aguda la tendencia decreciente de la producción. Por ejemplo, con base en las cifras que reportó la cnh el 2 de agosto de 2015, la extracción de petróleo crudo y gas natural en los primeros siete meses de 2015 equivalió a 91.8 y $98.7 \%$, respectivamente, de las registradas en el mismo periodo del año anterior. Esta disminución reciente se ha debido a la merma acumulada de las reservas disponibles desde 1982, mismas que no se han restituido en la tasa requerida para soportar con nuevos descubrimientos los montos de extracción sostenidos desde ese año (cuadro 4).

\begin{tabular}{|c|c|c|c|}
\hline \multicolumn{4}{|l|}{ Cuadro 4} \\
\hline \multicolumn{4}{|c|}{ Producción y restitución integral de reservas, años y periodos seleccionados } \\
\hline \multirow{2}{*}{ Periodo/Año } & Producción & Adición de reservas (1) & \multirow{2}{*}{$\begin{array}{l}\text { Tasa integral de restitución } \\
\text { (puntos porcentuales) }\end{array}$} \\
\hline & \multicolumn{2}{|c|}{ (Millones de barriles de petróleo crudo equivalente) } & \\
\hline & & \multicolumn{2}{|c|}{ Reservas 3P } \\
\hline $1980-1984$ & 6249 & 32196 & 515 \\
\hline $1985-1989$ & 6435 & 1135 & 18 \\
\hline $1990-1994$ & 6518 & 3288 & 50 \\
\hline \multirow[t]{2}{*}{ 1995-1999 } & 7134 & 2118 & 30 \\
\hline & & \multicolumn{2}{|c|}{ Reservas probadas (1P) } \\
\hline 2003 & 1587 & 405 & 26 \\
\hline 2004 & 1611 & 365 & 23 \\
\hline 2005 & 1604 & 424 & 26 \\
\hline 2006 & 1618 & 663 & 41 \\
\hline 2007 & 1603 & 806 & 50 \\
\hline 2008 & 1451 & 1042 & 72 \\
\hline 2009 & 1378 & 1063 & 77 \\
\hline 2010 & 1385 & 1188 & 86 \\
\hline 2011 & 1359 & 1373 & 101 \\
\hline 2012 & 1353 & 1411 & 104 \\
\hline 2013 & 1333 & 904 & 68 \\
\hline 2014 & 1291 & 870 & 67 \\
\hline
\end{tabular}

Fuente: elaboración propia con información de Petróleos Mexicanos: Anuarios Estadísticos, Base de Datos Institucional e Informes Anuales. (1) Partida obtenida mediante la diferencia entre Variación en las reservas y Producción, incluye descubrimientos, delimitaciones, desarrollos y revisiones.

Durante los últimos tres quinquenios del siglo pasado, la tasa integral de restitución de reservas totales petroleras fue sistemáticamente inferior a $100 \%$ (18, 50 y $30 \%$, como se aprecia en el cuadro 4). En 1999 se modificaron los criterios de definición y desagregación en probadas, probables y posibles, y a partir de 2002 dichos criterios se apegan a lo establecido por la Securities and Exchange Commission (Comisión de Valores y Bolsas) de Estados Unidos, especialmente en lo que hace a las reservas probadas, de mayor incidencia en la toma de decisiones. La tasa anual de restitución de estas últimas, en promedio $62 \%$ en el periodo 2003-2014, también resultó inferior a 100\%, con la excepción de 2011 y 2012, únicos años en Pemex rebasó ligeramente el objetivo de restitución. La 
estabilidad en los volúmenes de extracción durante varias décadas, fincada en el aprovechamiento de la riqueza petrolera previamente acumulada y la insuficiente reposición de la misma, se constituyó en un patrón de comportamiento que se extendió también a la refinación de petróleo y a otras actividades del sector de hidrocarburos.

\begin{tabular}{|c|c|c|c|c|c|c|c|}
\hline \multicolumn{8}{|l|}{ Cuadro 5} \\
\hline \multicolumn{8}{|c|}{ Producción de petrolíferos, 1982-2015 (Miles de barriles diarios) } \\
\hline Año & Total & $\begin{array}{c}\text { Gas } \\
\text { licuado }\end{array}$ & Gasolina & Querosenos & Diesel & Combustóleo & Otros \\
\hline 1982 & 1237 & 151 & 348 & 76 & 231 & 350 & 82 \\
\hline 1983 & 1248 & 155 & 355 & 67 & 224 & 350 & 98 \\
\hline 1984 & 1326 & 155 & 363 & 66 & 233 & 375 & 134 \\
\hline 1985 & 1381 & 167 & 366 & 65 & 246 & 398 & 140 \\
\hline 1986 & 1353 & 183 & 371 & 61 & 243 & 405 & 89 \\
\hline 1987 & 1403 & 193 & 379 & 72 & 232 & 425 & 103 \\
\hline 1988 & 1403 & 207 & 385 & 72 & 206 & 421 & 113 \\
\hline 1989 & 1460 & 218 & 394 & 68 & 234 & 427 & 119 \\
\hline 1990 & 1465 & 243 & 402 & 66 & 256 & 426 & 73 \\
\hline 1991 & 1494 & 250 & 398 & 71 & 276 & 417 & 82 \\
\hline 1992 & 1495 & 244 & 383 & 76 & 278 & 421 & 92 \\
\hline 1993 & 1551 & 254 & 417 & 84 & 267 & 419 & 110 \\
\hline 1994 & 1596 & 267 & 430 & 85 & 284 & 420 & 110 \\
\hline 1995 & 1530 & 257 & 423 & 77 & 255 & 417 & 103 \\
\hline 1996 & 1510 & 249 & 417 & 69 & 270 & 418 & 89 \\
\hline 1997 & 1453 & 215 & 388 & 59 & 275 & 426 & 88 \\
\hline 1998 & 1525 & 225 & 412 & 59 & 290 & 446 & 93 \\
\hline 1999 & 1485 & 232 & 406 & 59 & 272 & 428 & 89 \\
\hline 2000 & 1450 & 229 & 393 & 56 & 265 & 423 & 84 \\
\hline 2001 & 1473 & 233 & 390 & 57 & 282 & 436 & 75 \\
\hline 2002 & 1481 & 236 & 399 & 57 & 267 & 450 & 73 \\
\hline 2003 & 1556 & 246 & 446 & 60 & 308 & 397 & 100 \\
\hline 2004 & 1588 & 254 & 468 & 62 & 325 & 368 & 112 \\
\hline 2005 & 1555 & 247 & 456 & 63 & 318 & 351 & 120 \\
\hline 2006 & 1546 & 241 & 457 & 65 & 328 & 325 & 130 \\
\hline 2007 & 1512 & 226 & 456 & 66 & 334 & 301 & 128 \\
\hline 2008 & 1491 & 209 & 452 & 64 & 344 & 289 & 134 \\
\hline 2009 & 1525 & 209 & 472 & 57 & 337 & 316 & 134 \\
\hline 2010 & 1416 & 212 & 425 & 52 & 290 & 322 & 116 \\
\hline 2011 & 1379 & 209 & 401 & 56 & 274 & 307 & 131 \\
\hline 2012 & 1405 & 204 & 418 & 57 & 300 & 273 & 153 \\
\hline 2013 & 1457 & 206 & 437 & 61 & 313 & 269 & 170 \\
\hline 2014 & 1385 & 205 & 422 & 53 & 287 & 259 & 159 \\
\hline $\begin{array}{l}2015 \\
\text { (Al mes } \\
\text { de mayo) }\end{array}$ & 531 & 77 & 163 & 21 & 115 & 89 & 67 \\
\hline
\end{tabular}

Fuente: elaboración propia con información de Secretaría de Energía: Sistema de Información Energética. 
En el período 1982-2014 la producción de petrolíferos promedió anualmente 1459 miles de barriles diarios (mbd), con una variabilidad de no más, ni menos, de $8 \%$ respecto de la media (cuadro 5). Algo similar sucedió con el gas, aunque en un margen menos estrecho.

Tradicionalmente ha existido un desacoplamiento entre el tipo de crudo que puede ser refinado de manera eficiente por las refinerías en operación no reconfiguradas (Salamanca, Tula y Salina Cruz) y el que mayormente se extrae en el país. Al anunciar la aprobación por el Departamento de Comercio de Estados Unidos de la exportación a México de hasta $100 \mathrm{mbd}$ de crudos ligeros y condensados, Pemex señaló que el país "produce mayormente crudo pesado, en tanto [esas] refinerías están configuradas para procesar crudo ligero", situación que afecta su rendimiento industrial y produce altos remanentes de combustóleo pesado, de difícil colocación en los mercados. Al introducir estos insumos importados en la mezcla para refinación la empresa espera que se eleve el rendimiento de gasolinas y diésel, al tiempo que se abate el residuo de combustóleo.2

La situación de la petroquímica fue distinta a diferencia de lo ocurrido en la producción de petrolíferos. Se caracterizó por un rápido crecimiento desde principios de la década de 1980, que culminó en el último lustro del siglo pasado con los volúmenes de producción más altos registrados en la historia del país. Ulteriormente se observó un franco retroceso, que aún continúa y que la regresó a los niveles de producción de principios de la década de 1980. A partir de las disposiciones adoptadas en 1996 la producción petroquímica ha disminuido constantemente hasta situarse en 2014 en 59\% del nivel alcanzado en 1995 (cuadro 6).

La oferta de energía de otras fuentes, como la nuclear y diversas renovables, pese a su dinamismo, especialmente el de estas últimas en años recientes, no ha modificado la configuración determinada por la dependencia y estabilidad prevaleciente en la oferta nacional de hidrocarburos. Las energías renovables siguen constituyendo opciones de escasa cobertura nacional, en contraste con el desarrollo que se advierte en otras partes del mundo y con indicadores reveladores de su potencial en el país.

La capacidad para restituir reservas y ampliar y consolidar la base productiva en el sector de hidrocarburos al ritmo requerido por el mercado interno ha sido rígida debido a la acentuada tendencia a la baja de las inversiones, que sólo registraron una tardía e insuficiente recuperación en años recientes. El monto total de inversiones a precios constantes realizado en 1989 equivalió a sólo 22\% del observado en 1982; recuperó aquél nivel hasta 2008 y a partir de esta fecha observó un persistente aumento: en 2014 fue mayor en 48\% (gráfica 3).

2 Pemex, "El intercambio de crudo ligero de Estados Unidos con México mejorará la producción de diésel y gasolina en el país", boletín nacional 79, 14 de agosto de 2015 (http://www.pemex. com/saladeprensa/boletines_nacionales/Paginas/2015-079-nacional.aspx). 


\begin{tabular}{|c|c|c|c|c|c|c|}
\hline \multicolumn{7}{|l|}{ Cuadro 6} \\
\hline \multicolumn{7}{|c|}{ Producción de petroquímicos, 1990-2015 (Miles de toneladas) } \\
\hline Año & Total & $\begin{array}{l}\text { Derivados } \\
\text { del metano }\end{array}$ & $\begin{array}{c}\text { Derivados } \\
\text { del etano }\end{array}$ & $\begin{array}{l}\text { Aromáticos } \\
\text { y derivados }\end{array}$ & $\begin{array}{c}\text { Propileno y } \\
\text { derivados }\end{array}$ & Otros \\
\hline 1990 & 17592 & 6402 & 3116 & 2088 & 524 & 5462 \\
\hline 1991 & 18012 & 6634 & 2967 & 2081 & 598 & 5733 \\
\hline 1992 & 19121 & 6525 & 3377 & 2039 & 622 & 6558 \\
\hline 1993 & 17776 & 5258 & 3087 & 1792 & 535 & 7105 \\
\hline 1994 & 19142 & 5996 & 3048 & 1932 & 602 & 7563 \\
\hline 1995 & 19271 & 5945 & 3140 & 1914 & 720 & 7553 \\
\hline 1996 & 18371 & 6068 & 3087 & 1811 & 705 & 6701 \\
\hline 1997 & 15980 & 5205 & 3089 & 1504 & 608 & 5574 \\
\hline 1998 & 14656 & 4549 & 2955 & 1402 & 453 & 5297 \\
\hline 1999 & 12823 & 3153 & 2696 & 1235 & 307 & 5432 \\
\hline 2000 & 11501 & 2358 & 2636 & 667 & 471 & 5369 \\
\hline 2001 & 10377 & 1869 & 2408 & 642 & 337 & 5120 \\
\hline 2002 & 9880 & 1747 & 2309 & 670 & 392 & 4763 \\
\hline 2003 & 10298 & 1419 & 2218 & 795 & 461 & 5406 \\
\hline 2004 & 10731 & 1678 & 2073 & 1222 & 509 & 5249 \\
\hline 2005 & 10603 & 1268 & 2440 & 1187 & 462 & 5246 \\
\hline 2006 & 10961 & 1436 & 2748 & 1089 & 349 & 5339 \\
\hline 2007 & 11757 & 1883 & 2526 & 1338 & 392 & 5619 \\
\hline 2008 & 11973 & 2224 & 2450 & 1354 & 338 & 5607 \\
\hline 2009 & 11956 & 1992 & 2489 & 1233 & 451 & 5791 \\
\hline 2010 & 13192 & 2305 & 2635 & 1525 & 453 & 6274 \\
\hline 2011 & 12384 & 2321 & 2538 & 1285 & 418 & 5822 \\
\hline 2012 & 10694 & 2486 & 2563 & 189 & 484 & 4973 \\
\hline 2013 & 11478 & 2475 & 2292 & 1088 & 462 & 5161 \\
\hline 2014 & 11319 & 2374 & 1897 & 1214 & 526 & 5307 \\
\hline $\begin{array}{l}2015 \\
\text { (Ene-mayo) }\end{array}$ & 4590 & 889 & 816 & 509 & 216 & 2161 \\
\hline
\end{tabular}

Fuente: elaboración propia con información de Secretaría de Energía: Sistema de Información Energética.

En lo que se refiere al destino de la inversión, la prelación prioritaria y tradicional ha sido desde 1982 acelerar o evitar la caída en la extracción de petróleo, con el criterio de maximizar en lo inmediato los ingresos fiscales, más que armonizar ese objetivo con los de exploración y transformación primaria de los hidrocarburos extraídos del subsuelo (cuadro 7). 


\section{Gráfica 3}

Inversiones en el sector de hidrocarburos, 1979-2015

(Millones de pesos constantes de 2012)

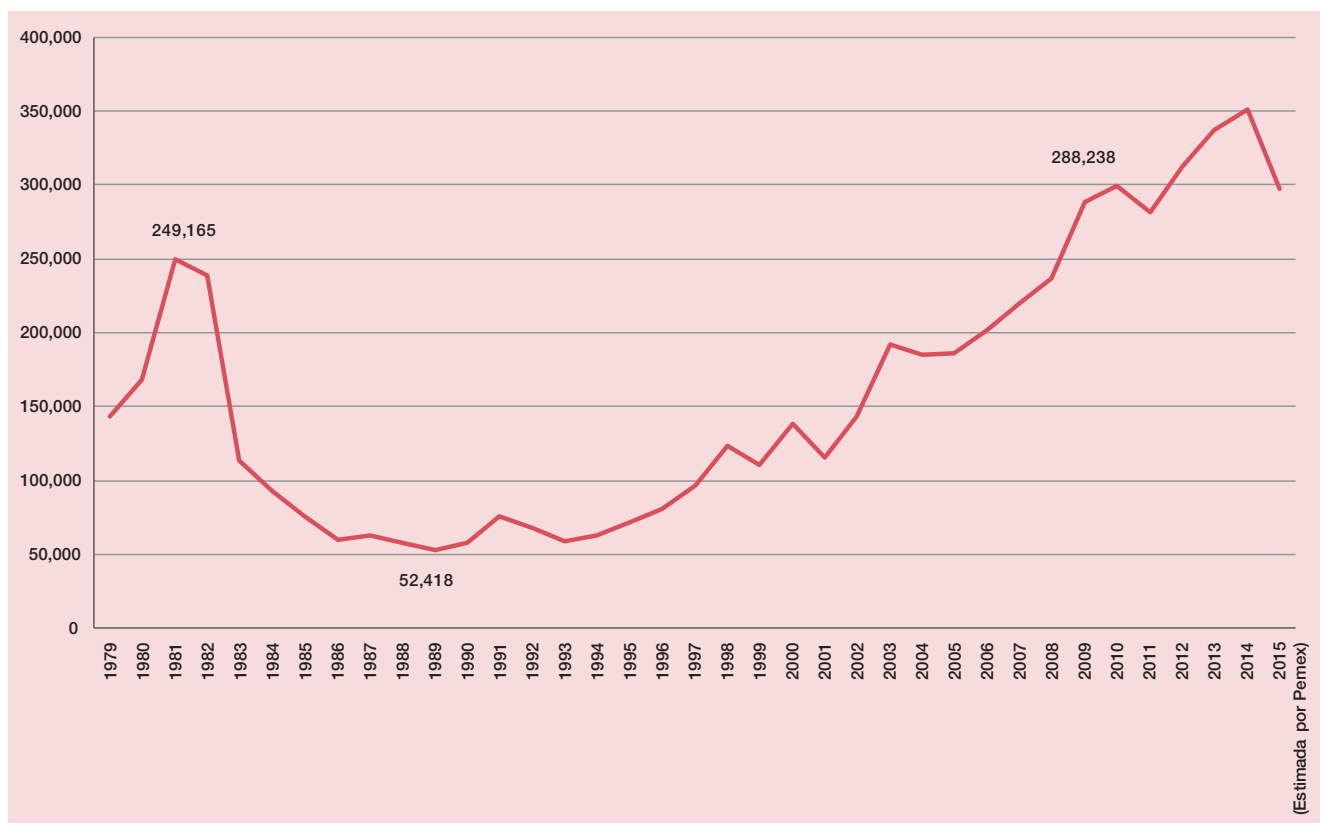

Fuente: elaboración propia con información de Petróleos Mexicanos: Anuarios Estadísticos, Memorias de Labores, Relación con Inversionistas.

Lo anterior contribuye a explicar que se haya mantenido relativamente estable la extracción, sin reponer al mismo tiempo las reservas y sin consolidar y ampliar la capacidad de refinación, de proceso de gas y de infraestructura para el transporte, almacenamiento y distribución de hidrocarburos.

\section{Vulnerabilidad y tendencia estructural al desequilibrio externo y de finanzas públicas}

La relativa rigidez de la oferta nacional de energía contrasta con la presión y los requerimientos crecientes de la demanda de hidrocarburos para el mercado interno, que han sido moderados pero sostenidos y acumulados. El consumo nacional de petrolíferos y gas natural registró, en promedio, tasas de crecimiento anual de 1.2 y $3.3 \%$ entre 1989 y 2014. Estos aumentos, ante la relativa inflexibilidad de la producción nacional, han dado lugar a un creciente contenido importado, que en 2015 alcanzó niveles significativos: petrolíferos 39.3\% y gas natural 16.4\% (cuadro 8). 


\section{Cuadro 7}

Inversiones de petróleos mexicanos en producción primaria y transformación industrial, 1991-2013 (Millones de pesos corrientes)

\begin{tabular}{|c|c|c|c|}
\hline Año & Total & $\begin{array}{l}\text { Extracción y } \\
\text { exploración }\end{array}$ & $\begin{array}{c}\text { Transformación } \\
\text { industrial (1) }\end{array}$ \\
\hline 1991 & 9038 & 5181 & 3857 \\
\hline 1992 & 9059 & 5274 & 3785 \\
\hline 1993 & 8468 & 5208 & 3260 \\
\hline 1994 & 10009 & 5658 & 4351 \\
\hline 1995 & 15841 & 9656 & 6184 \\
\hline 1996 & 23545 & 16748 & 6797 \\
\hline 1997 & 33678 & 24216 & 9462 \\
\hline 1998 & 50010 & 37663 & 12347 \\
\hline 1999 & 52382 & 41080 & 11302 \\
\hline 2000 & 71725 & 44654 & 27071 \\
\hline 2001 & 62938 & 53446 & 9492 \\
\hline 2002 & 80759 & 63000 & 17759 \\
\hline 2003 & 113687 & 88380 & 25307 \\
\hline 2004 & 122863 & 113332 & 9531 \\
\hline 2005 & 126988 & 112863 & 14125 \\
\hline 2006 & 150397 & 130071 & 20326 \\
\hline 2007 & 170111 & 148761 & 21349 \\
\hline 2008 & 201740 & 178104 & 23635 \\
\hline 2009 & 251882 & 226802 & 25080 \\
\hline 2010 & 268599 & 239409 & 29191 \\
\hline 2011 & 267261 & 235942 & 31319 \\
\hline 2012 & 311993 & 274745 & 37247 \\
\hline 2013 & 328572 & 287663 & 40909 \\
\hline
\end{tabular}

Fuente: elaboración propia con información de Petróleos Mexicanos: Anuarios Estadísticos. (1) Incluye Corporativo de Pemex.

\section{Cuadro 8}

Contenido importado de petrolíferos y gas natural, años seleccionados 1979-2015 (Puntos porcentuales)

\begin{tabular}{|l|c|c|}
\hline \multicolumn{1}{|c|}{ Año } & Petrolíferos & Gas natural \\
\hline 1979 & 2.8 & N/D \\
\hline 1980 & 1.3 & N/D \\
\hline 1985 & 4.1 & N/D \\
\hline 1990 & 7.4 & 1.2 \\
\hline 1995 & 9.0 & 4.4 \\
\hline 2000 & 21.3 & 4.7 \\
\hline 2005 & 19.6 & 9.1 \\
\hline 2010 & 33.9 & 7.1 \\
\hline 2014 & 35.1 & 17.2 \\
\hline
\end{tabular}

Fuent: elaboración propia con información de Secretaría de Energía: Sistema de Información Energética y Petróleos Mexicanos: Anuarios Estadísticos. N/D: No disponible. 
De este modo, la brecha creciente entre oferta y demanda se ha cubierto mediante importaciones que menguaron paulatinamente lo que fue el tradicional superávit de la balanza comercial petrolera. Por primera vez en más de tres décadas, dicho excedente se tornó en déficit de más de 2 mil millones de dólares en los primeros cinco meses de 2015, equivalente a casi la tercera parte de los ingresos obtenidos por la exportación de petróleo crudo en ese período (cuadro 9).

\section{Cuadro 9}

Saldo de la balanza comercial petrolera, años seleccionados 1990-2015 (Millones de dólares)

\begin{tabular}{|l|r|r|r|r|r|}
\hline \multicolumn{1}{|c|}{ Año } & Total & Petróleo crudo & Gas natural & Petrolíferos & Petroquímicos \\
\hline 1990 & 8977 & 8900 & -31 & -36 & 144 \\
\hline 1995 & 5985 & 7420 & -96 & -562 & -777 \\
\hline 2000 & 8151 & 14553 & -381 & -3486 & -2535 \\
\hline 2005 & 15495 & 28329 & -2650 & -5257 & -4928 \\
\hline 2010 & 11482 & 35919 & -2132 & -14830 & -7474 \\
\hline 2014 & 1097 & 35855 & -5201 & -20537 & -9021 \\
\hline $\begin{array}{l}\text { (Al mes de } \\
\text { mayo) }\end{array}$ & -2673 & 8554 & -1519 & -6765 & -2943 \\
\hline
\end{tabular}

Fuente: elaboración propia con información de Petroleos Mexicanos: Memorias de Labores y Grupo de Trabajo de Estadísticas de Comercio Exterior, integrado por Banco de México, Instituto Nacional de Estadística y Geografía, Servicio de Administración Tributaria y Secretaría de Economía. Nota: La suma de los parciales puede no coincidir con el total debido al redondeo de las cifras.

En lo que alude a la demanda externa, la restricción productiva en la extracción ha limitado la posibilidad de insertarse con flexibilidad en los mercados del exterior y ha dado lugar a la disminución de la participación de México en el mercado mundial de petróleo crudo desde principios de la década de 1980. Como "tomador" de precios internacionales de petróleo crudo, el país no aprovecha la posibilidad de ajustar las exportaciones a las circunstancias fluctuantes de la demanda externa y las cotizaciones internacionales. Por ejemplo, el auge de las cotizaciones observado desde mediados de la década anterior hasta 2014 coincide con la disminución y no con el aumento de los volúmenes exportados, como en todo caso hubiera sido deseable ante la ventaja de precios más elevados (cuadro 10 y gráfica 4). En adición, el crudo mexicano destinado a la exportación se mantiene desde 1982 relativamente constante respecto a la extracción, entre 47 y $57 \%$, sin variar la proporción ante los cambios en los precios internacionales (gráfica 5). 


\begin{tabular}{|l|c|c|}
\hline \multicolumn{2}{|l|}{\begin{tabular}{l} 
Cuadro 10 \\
\hline Precio y volumen de exportación de petróleo crudo, años seleccionados 1982-2015
\end{tabular}} \\
\hline Año & $\begin{array}{c}\text { Precio promedio anual (2) } \\
\text { (Dólar por barril) }\end{array}$ & $\begin{array}{c}\text { Volumen de exportación anual } \\
\text { (Millones de barriles) }\end{array}$ \\
\hline 1982 & 28.8 & 552 \\
\hline 1985 & 25.4 & 532 \\
\hline 1990 & 18.8 & 466 \\
\hline 1995 & 15.7 & 476 \\
\hline 2000 & 24.6 & 603 \\
\hline 2005 & 42.8 & 663 \\
\hline 2010 & 72.3 & 496 \\
\hline 2014 & 86.6 & 417 \\
\hline 2015 (1) & 49.2 & 425 \\
\hline
\end{tabular}

Fuente: elaboración propia con información de Instituto Nacional de Estadística y Geografía: Banco de Información Económica. (1) Precio promedio al primer semestre y volumen mensual promedio al primer semestre anualizado. (2) Mezcla.

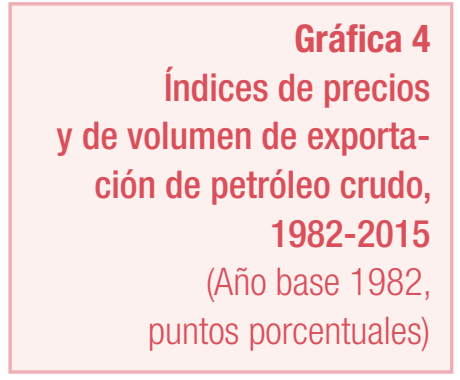

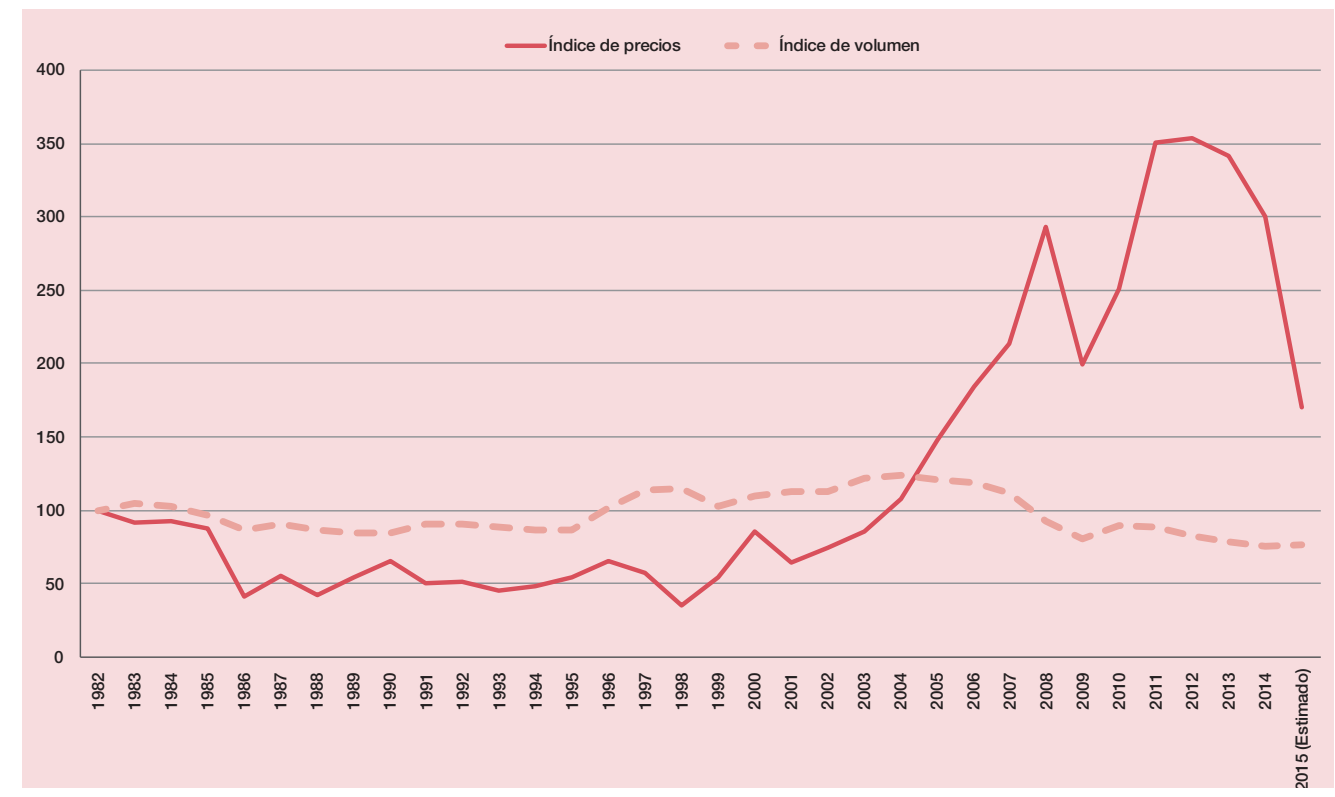

Fuente: elaboración propia con información de Instituto Nacional de Estadística y Geografía: Banco de Información Económica.

En suma, las señales de las demandas interna y de exportación no se reflejan en el comportamiento de la producción nacional de hidrocarburos, al menos hasta los años recientes en que la estabilidad de la producción se ha tornado difícil de sostener. En lo internacional, la relación de exportaciones a reservas de México es una de las más altas. Con cifras de 2014, se encuentra que en ese año México exportó alrededor de $8 \%$ de sus reservas, en tanto que otros países exportadores destinaron al exterior proporciones inferiores o muy inferiores. Por ejemplo, Kazajstán (1.6\%), 


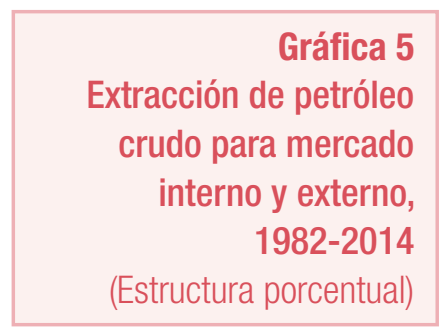

Nigeria (1.8\%), Ecuador (2.4\%), Argelia (3.5\%), Brasil (5.5\%) Malasia (6\%) y Angola (7.1\%). A la reducción ya señalada de las reservas mexicanas no siguió una moderación de las exportaciones, en función de la seguridad energética de la nación. ${ }^{3}$

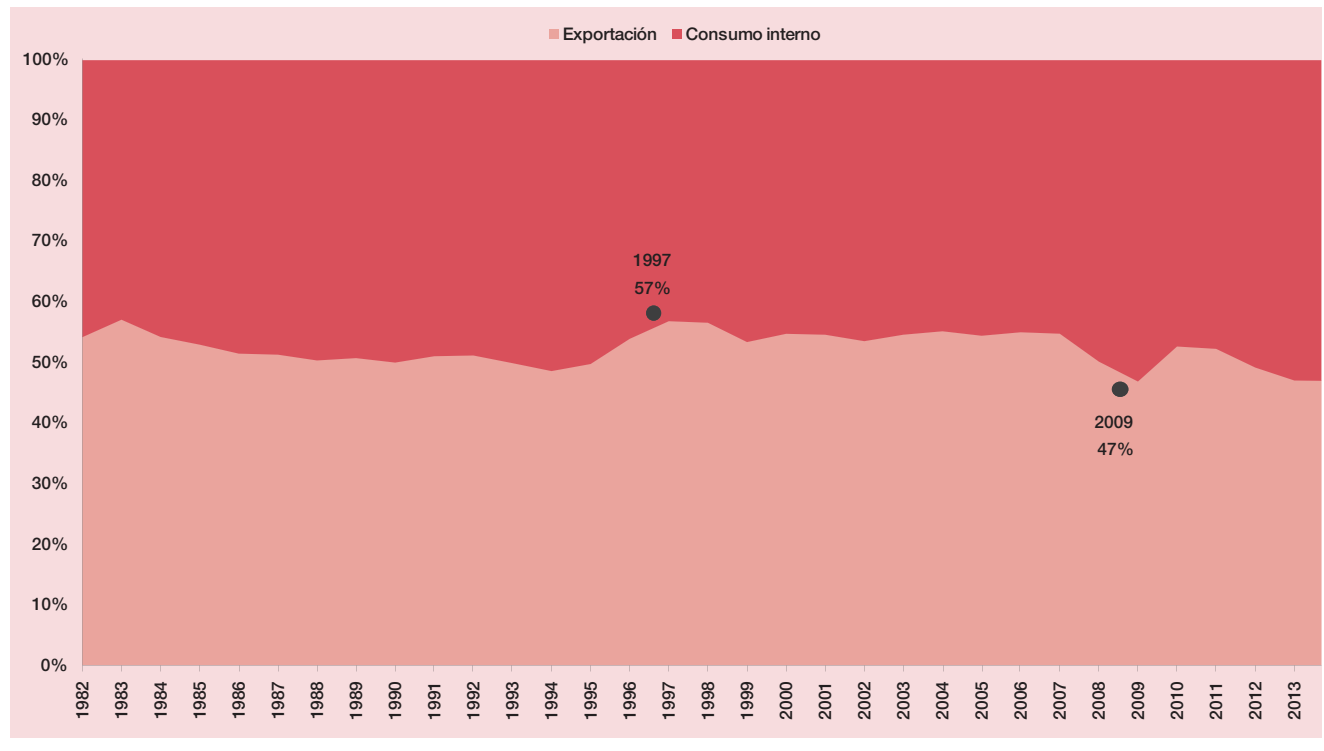

Fuente: elaboración propia con información de Instituto Nacional de Estadística y Geografía: Banco de Información Económica y Petróleos Mexicanos: Anuarios Estadísticos e Informes Anuales

El auge en la expansión petrolera durante las décadas de 1970 y 1980 influyó de manera determinante en el comportamiento y configuración de las finanzas públicas del país. Parte importante de la recaudación fiscal proviene de derechos y aprovechamientos por el uso de los recursos naturales propiedad de la Nación. Desde entonces las aportaciones impositivas de los contribuyentes fueron parcialmente sustituidas por la captación de estos recursos. El sistema fiscal mexicano quedó condicionado a esta importante fuente de ingresos. La recaudación fiscal proveniente de la actividad petrolera ha sido determinante en los ingresos presupuestales del gobierno federal. Promedia más de $30 \%$ en las últimas décadas, dentro de un rango de entre 19 y $50 \%$ anual. En el primer semestre de 2015 se redujo a 18\%. Como proporción del PIB, la recaudación petrolera promedió 7 puntos (cuadro 11). Las cifras de ingresos petroleros excluyen la recaudación del IVA y IEPS asociados a la actividad petrolera y las coberturas de riesgos por baja de precio del crudo.

3 OPEC Annual Statistical Bulletin 2015 (http://www.opec.org/opec_web/static_files_project/media /downloads/publications/ASB2015.pdf). 


\begin{tabular}{|c|c|c|c|c|c|}
\hline \multicolumn{6}{|l|}{ Cuadro 11} \\
\hline \multicolumn{6}{|c|}{$\begin{array}{l}\text { Ingresos presupuestales del sector público, petroleros y no petroleros, } \\
\text { años seleccionados } 1977-2014\end{array}$} \\
\hline \multirow[t]{2}{*}{ Año } & Total & Petroleros & No petroleros & Petroleros & No petroleros \\
\hline & \multicolumn{3}{|c|}{ (Porcentaje del Producto Interno Bruto) } & \multicolumn{2}{|c|}{ (Estructura porcentual) } \\
\hline 1980 & 19.3 & 6.2 & 13.0 & 32.3 & 67.7 \\
\hline 1985 & 24.6 & 11.3 & 13.3 & 46.0 & 54.0 \\
\hline 1990 & 20.5 & 5.6 & 14.9 & 27.4 & 72.6 \\
\hline 1995 & 19.0 & 5.5 & 13.4 & 29.1 & 70.9 \\
\hline 2000 & 18.2 & 4.9 & 13.3 & 27.1 & 72.9 \\
\hline 2005 & 20.6 & 7.5 & 13.1 & 36.4 & 63.6 \\
\hline 2010 & 22.3 & 7.7 & 14.6 & 34.7 & 65.3 \\
\hline 2014 & 23.2 & 7.1 & 16.1 & 30.7 & 69.3 \\
\hline 2015 (Al mes de mayo) & N/D & N/D & N/D & 17.8 & 82.2 \\
\hline
\end{tabular}

Fuente: elaboración propia con información de Instituto Nacional de Estadística y Geografía: Banco de Información Económica y Banco de México: Ingresos Presupuestales del Sector Público. N/D: No disponible.

La dependencia fiscal de la extracción de hidrocarburos, en especial del petróleo crudo, se arraigó como una de las restricciones fundamentales en el diseño de la política económica y del mantenimiento de la estabilidad financiera de la economía. En efecto, maximizar la "plataforma petrolera" en unidades físicas y fijar cifras previsibles de la cotización internacional del crudo y del tipo de cambio, se afianzaron como imperativos insoslayables en la elaboración de los presupuestos de egresos e ingresos de la federación. Sin embargo, esos requerimientos no necesariamente guardan correspondencia con la capacidad de extracción y exploración y con las posibilidades de generación de recursos de Pemex como entidad productiva a cargo de atender con eficiencia esas actividades. La tensión -y con frecuencia el conflicto- entre ambos propósitos se ha resuelto por la vía de limitar las capacidades financieras y de producción del organismo, e incluso de incurrir en ineficiencias en la explotación de las reservas petroleras, con los perjuicios previsibles en una de las más importantes fuentes de generación recaudatoria del gobierno federal.

La carga fiscal de Pemex, ahora en calidad de EPE y antes de organismo público descentralizado, es sumamente gravosa, no sólo en términos de los resultados de operación que ofrece y de la solvencia económica y financiera que requiere para atender su objetivo, sino también al establecer comparaciones con las principales empresas internacionales y entidades estatales en su ramo. Tradicionalmente Pemex se ha ubicado como una de las primeras petroleras del mundo en la generación de utilidades brutas. Sin embargo, desde 1998, con excepción de 2006 y 2012, los montos que paga al fisco superan sistemáticamente su rendimiento o utilidad de operación, después de cubrir los costos financieros. El efecto inevitable ha sido el deterioro financiero crónico de la entidad (cuadro 12). 


\section{Cuadro 12}

Resultados financieros de operación de petróleos mexicanos, 1993-2015

(Miles de millones de pesos)

\begin{tabular}{|c|c|c|c|c|}
\hline Año & Ventas totales & $\begin{array}{l}\text { Utilidad antes de } \\
\text { impuestos y de- } \\
\text { rechos }\end{array}$ & $\begin{array}{l}\text { Utilidad } \\
\text { (pérdida) neta }\end{array}$ & $\begin{array}{l}\text { Utilidad } \\
\text { (pérdida) integral }\end{array}$ \\
\hline 1993 & 65 & 30 & 3 & 3 \\
\hline 1994 & 73 & 36 & 3 & 3 \\
\hline 1995 & 140 & 85 & 10 & 10 \\
\hline 1996 & 212 & 142 & 16 & 16 \\
\hline 1997 & 226 & 130 & 8 & 8 \\
\hline 1998 & 191 & 76 & -10 & -10 \\
\hline 1999 & 246 & 102 & -18 & -18 \\
\hline 2000 & 399 & 205 & -20 & -20 \\
\hline 2001 & 350 & 136 & -33 & -33 \\
\hline 2002 & 367 & 149 & -30 & -30 \\
\hline 2003 & 531 & 234 & -54 & -54 \\
\hline 2004 & 719 & 385 & -35 & -35 \\
\hline 2005 & 908 & 470 & -91 & -91 \\
\hline 2006 & 1062 & 614 & 31 & 31 \\
\hline 2007 & 1136 & 646 & -31 & -31 \\
\hline 2008 & 1329 & 660 & -112 & -112 \\
\hline 2009 & 1090 & 452 & -95 & -95 \\
\hline 2010 & 1282 & 607 & -47 & -47 \\
\hline 2011 & 1558 & 785 & -91 & -91 \\
\hline 2012 & 1647 & 905 & 3 & -374 \\
\hline 2013 & 1608 & 695 & -170 & 84 \\
\hline 2014 & 1587 & 481 & -266 & -531 \\
\hline $\begin{array}{l}2015 \text { (Resultados } \\
\text { preliminares del } 1 \\
\text { de enero al } 30 \text { de } \\
\text { junio) }\end{array}$ & 588 & 15 & -185 & -181 \\
\hline
\end{tabular}

Fuente: elaboración propia con información de Petróleos Mexicanos: Estados Financieros Consolidados. Nota. Para los periodos 1993-2002 y 2008-2015 el efecto de la inflación no es reconocido, mientas que para el periodo 2003-2007 es utilizada la norma B10.

Entre 1993 y 2014, Pemex cubrió en impuestos y derechos, en promedio, 110\% de su utilidad de operación neta anual; en el primer semestre de 2015 la tasa recaudatoria fue desproporcionada: 13 veces el monto de la utilidad de operación neta antes de impuestos (cuadro 13). 


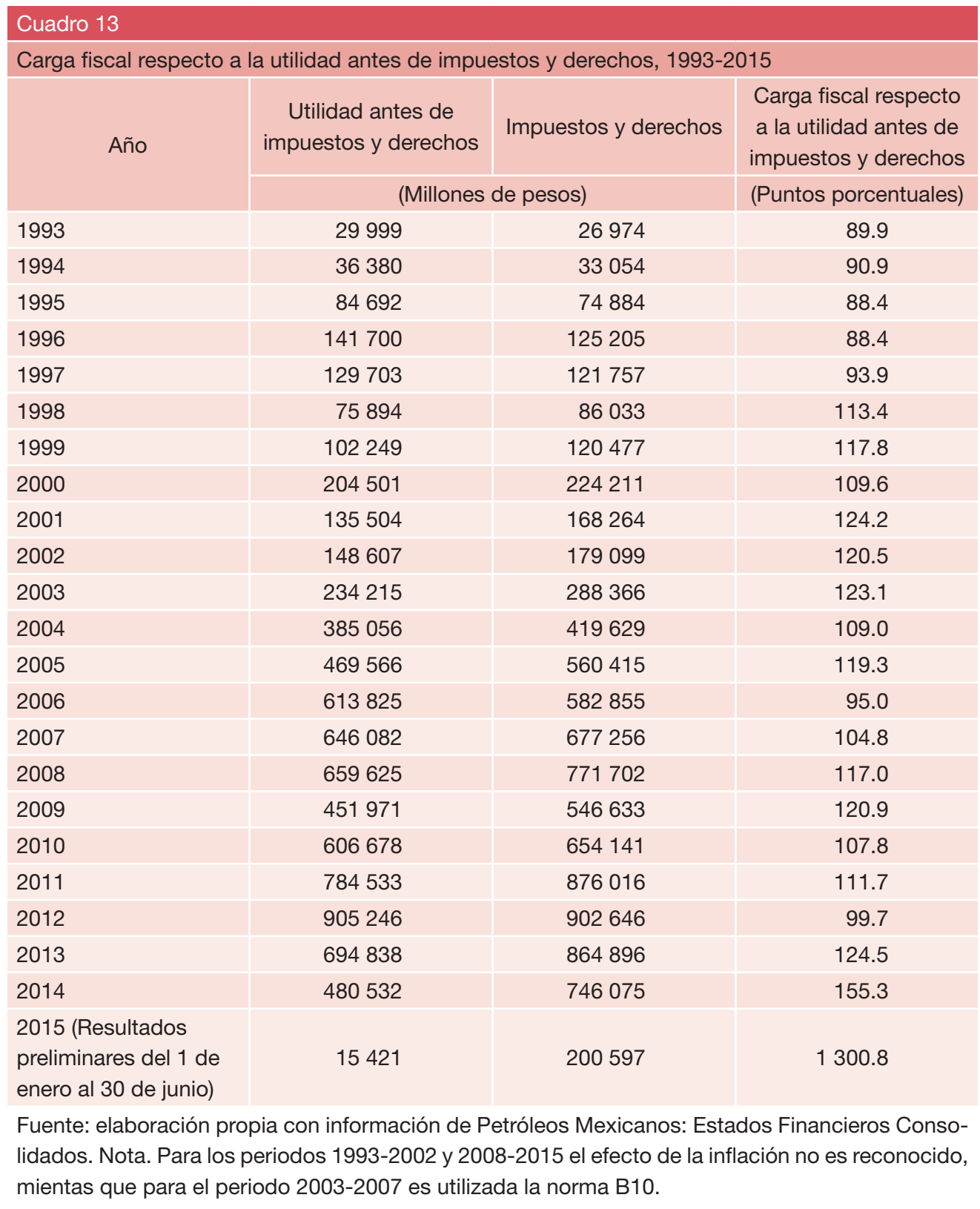

Al cierre de diciembre de 2014 y de junio de 2015 los pasivos del organismo superaron a sus activos en 36 y $44 \%$, respectivamente, arrojando cifras patrimoniales negativas sin precedente nacional o internacional (cuadro 14). Adviértase que este patrimonio negativo equivalió en 2014 a 4.5 puntos del PIB. 


\begin{tabular}{|c|c|c|c|}
\hline \multicolumn{4}{|l|}{ Cuadro 14} \\
\hline \multicolumn{4}{|c|}{ Activos, pasivos y patrimonio de petróleos mexicanos, 1993-2015 (Millones de pesos) } \\
\hline Año & Activos & Pasivos & Patrimonio \\
\hline 1993 & 153102 & 45294 & 107809 \\
\hline 1994 & 201518 & 83287 & 118232 \\
\hline 1995 & 244438 & 117836 & 126602 \\
\hline 1996 & 312049 & 156270 & 155780 \\
\hline 1997 & 344480 & 186329 & 158151 \\
\hline 1998 & 423168 & 249553 & 173615 \\
\hline 1999 & 490046 & 319171 & 170875 \\
\hline 2000 & 563468 & 412862 & 150605 \\
\hline 2001 & 556883 & 434017 & 122866 \\
\hline 2002 & 697379 & 596684 & 100696 \\
\hline 2003 & 845472 & 799611 & 45861 \\
\hline 2004 & 947527 & 914184 & 33343 \\
\hline 2005 & 1042560 & 1069430 & -20352 \\
\hline 2006 & 1204734 & 1164781 & 41652 \\
\hline 2007 & 1330281 & 1280373 & 51013 \\
\hline 2008 & 1236837 & 1209952 & 26885 \\
\hline 2009 & 1332037 & 1398877 & -66840 \\
\hline 2010 & 1392715 & 1506499 & -113783 \\
\hline 2011 & 1533345 & 1727264 & -193919 \\
\hline 2012 & 2024183 & 2295249 & -271066 \\
\hline 2013 & 2047390 & 2232637 & -185247 \\
\hline 2014 & 2128368 & 2896089 & -767721 \\
\hline $\begin{array}{l}2015 \text { (Resultados } \\
\text { preliminares al } \\
30 \text { de junio) }\end{array}$ & 2121733 & 3060176 & -938443 \\
\hline
\end{tabular}

Fuente: elaboración propia con información de Petróleos Mexicanos: Estados Financieros Consolidados. Nota. Para los periodos 1993-2002 y 2008-2015 el efecto de la inflación no es reconocido, mientas que para el periodo 2003-2007 es utilizada la norma B10.

Los resultados del primer semestre de 2015 se agravan respecto a la difícil situación prevaleciente en años anteriores, por las recientes caídas del precio del crudo y de los volúmenes de extracción. La pretensión manifestada por las autoridades es superar el impacto, al menos parcialmente, con recursos destinados a las actividades productivas de Pemex, la venta de activos, la suscripción de pasivos y la disminución del patrimonio. 4

4 Un ejemplo en este sentido se registró a finales de julio de 2015, cuando Pemex anunció la desinversión de su interés de 50\% en el capital social de Gasoductos de Chihuahua, con lo que la totalidad de la empresa pertenece ahora a IEnova, una empresa del grupo Sempra Energy, que, según su portal en internet (www.ienova.com.mx), desarrolla, construye y opera infraestructura de energía en México. "Los activos objeto de la transacción- aclara la nota informativa de Pemex - son tres gasoductos de gas natural, un etanoducto, un gasoducto de gas LP y una terminal de almacenamiento de gas LP." La transacción se evaluó en Dls. 1325 millones. Se in- 
La exportación de hidrocarburos es determinante de la disponibilidad constante de divisas que permite al Estado organizar el mercado cambiario e intervenir en el mismo para estabilizar el tipo de cambio. El saldo negativo de la balanza comercial petrolera restringe la capacidad de influir en el mercado cambiario con fines de estabilidad.

Contenido y alcance de la Reforma Energética La reforma energética constituye un elemento fundamental de la política económica. A iniciativa de la administración pública federal en funciones desde 2012, el Congreso aprobó once reformas estructurales que modificaron drásticamente el contenido, alcance y funciones del Estado mexicano. De acuerdo a la versión oficial, las reformas responden a tres propósitos:

\section{1) Elevar la productividad para detonar el crecimiento y desarrollo nacionales \\ 2) Fortalecer y ampliar los derechos de los ciudadanos \\ 3) Fortalecer el régimen político democrático}

El sentido más general de las reformas, como se establece en el Plan Nacional de Desarrollo 2013-2018, fue superar los resultados insatisfactorios que gravitan en el bienestar de la población, el crecimiento de la economía y la inclusión social; liberar las restricciones que limitan el aprovechamiento del potencial nacional y modernizar el Estado mexicano, en congruencia con los cambios generados por la globalización de los mercados y el avance de las sociedades desarrolladas. El énfasis de las reformas estructurales consiste en limitar las funciones de intervención del Estado en la economía y la sociedad a las de rectoría, regulación y promoción, a fin de inducir la creación de condiciones propicias para el desempeño de los particulares en una economía de mercados abiertos. Se pretende mejorar la calidad, competitividad y disponibilidad de los bienes y servicios que se ofrecen a la población, al tiempo de dotar al Estado de recursos suficientes para mitigar la pobreza y otras carencias congruentes con la inclusión social. Con la puesta en práctica de tales reformas, la expectativa en el horizonte de largo plazo es incidir en el crecimiento de la economía y lograr objetivos de desarrollo social. En el plazo inmediato la expectativa es incrementar la tasa de crecimiento del PIB hasta alcanzar 5.3 puntos porcentuales en 2018 , respecto a la inercia previsible de $3.5 \%$ sin la adopción de las reformas.

En contraste, otros análisis subrayan aspectos diferentes y acciones complementarias de política para restaurar el dinamismo de la actividad económica y el empleo, al tiempo que se impulse el bienestar social y se abata la pobreza y la desigualdad. Por ejemplo:

forma también que Pemex, "con los recursos obtenidos, podrá invertir en proyectos estratégicos de mayor rentabilidad, disminuyendo la necesidad de contratar deuda". Véase, Pemex, "Pemex monetiza su participación en la firma Gasoductos de Chihuahua mediante la firma de un convenio con IEnova", boletín nacional 72, 31 de julio de 2015. (http://www.pemex.com/saladeprensa/ boletines_nacionales/Paginas/2015-072-nacional.aspx). 
[...] tras los años de malos resultados económicos, parecería sensato replantear, o al menos someter a debate, algunos cambios de política macroeconómica, incluso si se da por hecho que las reformas estructurales estén operando o vayan a funcionar correctamente (a la fecha, el país sigue sin conocer detalle alguno sobre las metodologías y memorias de cálculo del impacto de las reformas sobre el crecimiento, la inversión, el empleo y la productividad, aunque ya se han realizado actos públicos para dar a conocer los resultados que se les atribuye.). Aún más, para que dichas reformas funcionen, se requerirá una revisión de los supuestos de política económica, que más bien propician el estancamiento.

[...] En especial, deben considerarse opciones para activar capacidades internas vinculadas a la demanda, sobre todo en la política de salarios, en el crédito y en la promoción de la inversión [...]. Se reconoce de forma unánime que continuamos con una brecha ante el producto potencial, pero siguen ausentes las políticas económicas activas de fomento. Hay, pues, elementos fundados para preguntarse qué previsiones pueden adoptarse ante la contingencia de que la economía no se recupere lo suficiente [...]

[...] No hemos superado las restricciones externas al crecimiento y, por ello, la idea de promover más activamente la recuperación con impulsos internos, está asociada a la propuesta de poner en marcha una estrategia intensa de política industrial y de encadenamientos productivos que aproveche las capacidades nacionales de abastecimiento [incluidas las de insumos energéticos]. 5

La reforma energética modificó la estructura y funciones del Estado mexicano. Los cambios constitucionales de diciembre de 2013 en materia de energía son profundos y de amplia repercusión, no sólo por lo que significan en el uso y transformación de la energía, sino por sus implicaciones para el conjunto de relaciones económicas, sociales, ambientales y políticas del país, cimentadas durante más de tres décadas en torno a las actividades de los hidrocarburos.

Los cambios constitucionales de 2013 modificaron el ámbito de participación del Estado en el funcionamiento del sistema energético nacional: restringieron la propiedad de la Nación a los hidrocarburos alojados en el subsuelo; acotaron las actividades exclusivas del Estado a las de exploración y extracción; hicieron permisible, mediante contratos, la participación de los particulares en dichas actividades; y asignaron a la extracción de hidrocarburos el objetivo de maximizar los ingresos del gobierno para financiar el desarrollo económico de largo plazo. Los cambios constitucionales se motivaron en el propósito de constituir mercados en los que los particulares, nacionales y extranjeros, pudieran participar con inversiones, tecnología y asunción de riesgos, y lograr ampliar la oferta de energía destinada a los mercados nacional y de exportación.

El propósito declarado de la reforma es transformar el funcionamiento del sistema energético nacional a fin de superar signos de inviabilidad evidenciados por dicho sistema en los últimos años y de superar la insuficiencia que muestran los resultados en cuanto su contribución al crecimiento, las finanzas públicas y la estabilidad de la

5 Memorándum: Grupo Nuevo Curso de Desarrollo ante la situación y la perspectiva económica y social, Universidad Nacional Autónoma de México, mayo de 2015, pp. 8-10. 
economía. La perspectiva que se ofrece es modificar la organización institucional, a fin de crear mercados de energía abiertos, competitivos, globales y modernos, que permitirían aprovechar el patrimonio de la Nación en materia de hidrocarburos.

El punto de vista alternativo sobre la reforma energética, formulado a lo largo del debate legislativo de las propuestas de cambios constitucionales y reglamentarios y reiterado tras la aprobación de las reformas, subrayó cuestiones como las siguientes:

- El cambio de paradigma que encierra la reforma energética tiene como esencia la apertura jurídica e institucional, casi irrestricta, a la inversión privada; el repliegue en las funciones reservadas en exclusividad al Estado y la reducción del ámbito de soberanía de la Nación sobre los hidrocarburos.

- Parece darse por hecho que la reforma provocará una reacción favorable de la inversión privada, especialmente la extranjera, convergente además con el interés nacional.

- Se asume, sin demostración o evidencia que vaya más allá de la argumentación doctrinaria general de las ventajas de la competencia y del mercado, que será posible maximizar la explotación de los hidrocarburos, generar mayores ingresos para el gobierno y revertir la tendencia decreciente del excedente petrolero.

- Ante el estancamiento crónico de la capacidad instalada de refinación y petroquímica, con la reforma se acentuará el sesgo exportador de petróleo crudo, característico del sector petrolero mexicano durante las últimas décadas, y se acentuará también el sesgo importador de hidrocarburos transformados.

- El nuevo paradigma petrolero así forjado constituye un retorno al prevaleciente hace un siglo, no muy diferente de un enclave primario exportador, soportado por la expectativa de que la inversión extranjera directa permita fortalecer el horizonte de explotación y extracción acelerada de los hidrocarburos.

La reforma energética se diseñó en un entorno global de relativo equilibrio y altos precios internacionales estables en los mercados petroleros mundiales. Esta situación cambió drásticamente desde mediados y sobre todo a finales de 2014, cuando ya se habían aprobado las disposiciones legales constitutivas de las reformas. Ahora se enfrenta una situación prolongada de excedentes de oferta mundial y cotizaciones equivalentes en general a la mitad de los máximos del primer semestre del año anterior. No se prevé una corrección pronta del desbalance del mercado internacional ni una recuperación significativa y sostenida de las cotizaciones al menos hasta finales de 2016 y quizá más adelante, dada la perspectiva de que la economía mundial entre en un periodo de estancamiento secular, caracterizado por tasas de crecimiento bajas y niveles elevados de desocupación y capacidades excedentes en diversas actividades productivas. El deterioro del entorno internacional no fue reconocido al definir la marcha de la implementación de la reforma energética sino hasta en fecha muy reciente, cuando, ante los resultados de la primera licitación internacional de contratos de exploración, en julio de 2015 , se aceptó la necesidad de reformular los términos y plazos de las convocatorias siguientes para hacerlos más atractivos. 
En todo caso, la asimetría acumulada entre la evolución resultante de los mercados interno y externo de hidrocarburos y la atonía de la oferta nacional constituyen determinantes estructurales que propician la urgente necesidad de modificar a fondo el funcionamiento del patrón energético mexicano.

\section{Pemex como eje de la reforma energética}

El debate político alrededor de la iniciativa de reforma constitucional y una vez aprobada, de la amplia y compleja legislación reglamentaria, se concentró en el subsector petrolero y en su organismo no sólo más importante, sino paradigmático: Pemex. Al mismo tiempo, parece indiscutible que el comportamiento de conjunto del sector de energía en México dependa críticamente de la operación de Pemex, cuyo rol dominante la reforma se propone transformar. La implementación de la reforma, por otra parte, se ha concentrado y ha sido más acelerada en Pemex que en otras entidades del sector de energía, ya existentes o recientemente establecidas.

Todo lo anterior hace aconsejable que el resto de este segundo apartado, a reserva de abordar en otro momento los demás extremos del conjunto de la reforma energética, se concentre en Pemex y en las acciones y decisiones que modifican su estructura organizativa y de operación. Como se advierte enseguida la EPE sigue inmersa en su implementación administrativa y aún no despega, ni puede evaluarse todavía, la operación real, cotidiana de un Pemex reformado.

\section{La reforma institucional y operativa de Pemex}

En el verano de 2015, año y medio después de aprobada la reforma constitucional en materia energética, se había avanzado y prácticamente concluido la transformación institucional y organizativa de Pemex como epe. El avance cubrió sobre todo los aspectos legales e institucionales; en los operativos la transición sigue en marcha. El tránsito de organismo público descentralizado a EPE entrañó una reformulación del cometido de la entidad y, más ampliamente, de su visión, misión y valores. Éstos, expresados como parte de la 'filosofía de la empresa', son los siguientes:

razón de ser: maximizar el valor del petróleo para México

misión: ser la empresa más competitiva de la industria petrolera mexicana y referente internacional

valores: decisiones en función del valor que aportan a Pemex

- Excelencia operativa y simplicidad administrativa

- Innovación y agilidad

- Satisfacción del cliente

- Honestidad y rendición de cuentas

- Trabajo en equipo para lograr las metas de Petróleos Mexicanos

- Orgullo de pertenecer a Petróleos Mexicanos6

6 Véase http://www.pemex.com/acerca/gobierno-corporativo/Paginas/mision.aspx (consultada el 3 de agosto de 2015). 
Sin embargo, se advierte que "el propósito de obtener ingresos para el Estado que contribuyan al desarrollo de largo plazo de la Nación" no encontró cabida explícita en la nueva formulación de la razón de ser, la misión y los valores de Pemex. ${ }^{7}$

\section{El Consejo de Administración}

\section{Integración del Consejo}

La integración del Consejo de Administración de Pemex, como EPE, quedó definida desde la reforma constitucional de diciembre de 2013. La fracción IV del artículo vigésimo transitorio del decreto de reforma estatuye que:

\section{[...] Para el caso de empresas productivas del Estado que realicen las actividades de exploración y extracción de petróleo y demás hidrocarburos sólidos, líquidos o gaseosos en términos de lo previsto por el párrafo séptimo del artículo 27 de esta Constitución, la ley deberá establecer, entre otras disposiciones, que su Consejo de Administración se conforme de la siguiente manera: cinco consejeros del Gobierno Federal, incluyendo el Secretario del Ramo en materia de Energía quien lo presidirá y tendrá voto de calidad, y cinco consejeros independientes. 8}

Al reflejar esta disposición constitucional en el Art. 15 de la Ley de Petróleos Mexicanos, ${ }^{9}$ el Congreso diferenció dos tipos de consejeros del gobierno federal: dos de ellos ex officio y tres de libre designación del presidente de la República. Éste designaría también a cinco consejeros independientes, sujetos a ratificación, por mayoría calificada, del Senado. Las diferencias más significativas, respecto del anterior Consejo, producto de la reforma de 2008, son el menor número de integrantes, de quince a diez; la exclusión de los consejeros representantes del Sindicato de Trabajadores Petroleros de la República Mexicana (STPRM), y el menor número y diferente calidad de los consejeros externos: se pasó de cuatro "consejeros profesionales", que representaban al Estado y eran servidores públicos, 10 a cinco "consejeros independientes", que no son servidores públicos y dedican sólo tiempo parcial a sus labores en el Consejo. El propio stprm no se opuso públicamente a su exclusión de dicho órgano. Otras organizaciones sindicales tampoco. Salvo la de la Organización de Cooperación y Desarrollo Económicos (OCDE). En un estudio ad hoc del secretariado

7 Podría inferirse que la incorporación de ese lenguaje a la reforma constitucional tuvo por fin colocar a la reforma energética dentro de las materias que la propia Constitución excluye de la consulta popular.

8 Véase "Decreto por el que se reforman y adicionan diversas disposiciones de la Constitución Política de los Estados Unidos Mexicanos, en Materia de Energía, Diario Oficial de la Federación, México, 20 de diciembre de 2013.

9 Véase "Ley de Petróleos Mexicanos", Diario Oficial de la Federación, México, 11 de agosto de 2014.

10 "Ley de Petróleos Mexicanos", Artículo 8, Diario Oficial de la Federación, México, 28 de noviembre de 2008. 
de la OCDE, preparado a solicitud de Pemex y del gobierno de México en 2010, se estima que participación de representantes de los trabajadores puede significar un activo para la labor y efectividad del Consejo. El estudio considera que:

\section{[...] La función del Consejo como cuerpo colegiado que, de manera conjunta, supervisa y establece estrategias para la empresa, puede verse fortalecida mediante la pericia única que aportan los representantes de los trabajadores. Sin embargo, el papel del Consejo puede verse debilitado si esos representantes se consideran a sí mismos como defen- sores de los intereses de los trabajadores -incluso en los casos en que estos intereses entren en conflicto con los objetivos de la empresa. 11}

La conclusión pudo haber sido otra: llevar al Consejo una voz que ofreciera, en palabras de la OCDE, "la pericia única que aportan los representantes de los trabajadores". ${ }^{12}$ Entre los criterios establecidos en Ley para integrar el Consejo de Administración de Pemex resultaron debatibles, en el caso de los consejeros independientes, los relativos a su obligada dedicación de tiempo parcial al encargo y al hecho de que no se les considere servidores públicos. Algunos se preguntaron si resultaba conveniente que la mitad de los integrantes del "órgano supremo de administración"13 de la mayor empresa productiva del Estado sólo dedicase tiempo parcial a sus tareas en el Consejo y se les excluyese de manera explícita de la calidad de servidor público, de la que se derivan atribuciones y responsabilidades, aunque ambas fueran a establecerse de manera ad hoc. El estudio de la OCDE, ya citado, reconoce la posibilidad de que pueda haber integrantes del Consejo provenientes de fuera del sector gubernamental, que dediquen tiempo parcial a sus funciones, "en el supuesto de que se encuentren formas de conferirles el estatus de 'funcionario público' en aquella parte de su tiempo que dediquen al trabajo del Consejo de Administración de Pemex."14

No dejó de advertirse que, en realidad, ninguno de los diez consejeros dedicará tiempo completo a su trabajo en el Consejo: los dos consejeros ex officio, por su

11 Véase OECD, "Corporate governance and board arrengements at Petróleos Mexicanos: Evaluation and recommendations", 1 de septiembre de 2010 (DAF/CA/SOPP(2005)FINAL/11Feb2013), p. 35.

12 Uno de los trabajos citados con mayor frecuencia sobre el rol de los representantes de los trabajadores en los órganos directivos de las empresas concluye que "un nivel adecuado de representación de los trabajadores en el Consejo puede incrementar la eficiencia y el valor de mercado de las empresas [...] La representación de los trabajadores proporciona un canal de comunicación confiable con los altos niveles de la empresa [y esta] mejor información mejora la toma de decisiones del Consejo mismo. [...] la inclusión de asientos para los trabajadores en el Consejo conduce también a un monitoreo adicional de los administradores [...]" Véase, Larry Fauver y Michael E Fuerst, "Does Good Corporate Governance Includes Employee Representation? Evidence from German Corporate Boards", Journal of Financial Economics, vol. 82, núm. 3, 2006, p. 703.

13 Así se conceptúa al Consejo de Administración en el párrafo preambular del Art 13 de la Ley. Véase "Ley de Petróleos Mexicanos", loc cit.

14 OECD, "Corporate governance and board arrengements at Petróleos Mexicanos...", loc cit, 104, p. 36 . 
calidad de secretarios de Estado; los tres consejeros del gobierno federal, porque se prevé que "podrán desempeñar otros empleos, cargos o comisiones", y los cinco independientes porque se estatuye que sólo dediquen tiempo parcial al encargo. Para mediados de septiembre de 2014 el Consejo de Administración de Pemex había quedado integrado y celebró su sesión de instalación el 7 de octubre de 2014.15

\section{Algunos aspectos de la operación y transparencia del Consejo}

Para mediados de agosto de 2015 han transcurrido casi seis meses desde la renuncia de un consejero independiente sin que haya sido sustituido. El Consejo ha celebrado siete sesiones, contando hasta la del 10 de julio, sin estar debidamente integrado. Parece que la falta de uno de cinco consejeros independientes se considera un detalle menor, que no merece ser subsanado. Se advierte también un deterioro de la oportunidad y un aumento de las limitaciones de la información pública de las deliberaciones y decisiones del Consejo y además, parece registrarse mayor demora en la divulgación de la información. Por otro lado, es creciente el número de temas en los que se reserva información, por lo general con el argumento de que su divulgación afectaría intereses comerciales de la empresa. En otro caso, se reservó, por cinco años, la síntesis de la deliberación del Consejo en materia de reorganización corporativa de Pemex.

\section{La estructura orgánica básica de Pemex, EPE}

El Estatuto Orgánico de Pemex establece, en su artículo 19, la nueva estructura orgánica básica de la empresa. ${ }^{16}$ Para analizarla conviene tener en mente el principio proclamado de que la empresa persigue la excelencia operativa y la simplicidad administrativa, pues la nueva estructura se expresa en una pirámide cuya base la integran 128445 trabajadores activos y 85839 jubilados $^{17}$ y en cuyos estratos superiores se ubican 188 gerencias, 57 subdirecciones, 13 direcciones corporativas o equivalentes y una dirección general. Si se atiende sólo a estos números, se encuentra que la estructura corporativa se amplió significtivamente respecto de la anterior:

\begin{tabular}{l|l|c|c|c|}
\hline \multicolumn{2}{l|}{ Cuadro 15} \\
\hline \multicolumn{2}{|l|}{ Pemex: estructura orgánica } \\
\hline
\end{tabular}

15 Véase Consejo de Administración, "Acta de la sesión de instalación", 7 de octubre de 2014 (www. pemex.com/acerca/gobierno-corporativo/acuerdos/Consejo\%202014/acta_878_instalacion.pdf).

16 Ibídem, pp. 49-55.

17 Auditoría Fiscal de la Federación, "Petróleos Mexicanos: Informe de la auditoría practicada al pasivo laboral”, México, julio de 2015, p. 57 (www.asf.gob.mx/uploads/56_informes_especiales_de_auditoria/ PEMEX_Interactivo/pdf). 
Más allá de los cambios de denominación, la Dirección Corporativa de Planeación, Coordinación y Desempeño puede ejemplificar la racionalidad que parece haber regido el nuevo diseño corporativo. A ésta se le encarga dirigir y alinear la planeación estratégica institucional, con vistas a la elaboración del Plan de Negocios de la empresa. Se establece una estructura piramidal a partir de 22 gerencias, que confluye en 7 subdirecciones y culmina en la dirección corporativa. En consecuencia, el potencial de traslapes y duplicaciones es enorme, pues la estructura orgánica básica de la empresa no parece cumplir los objetivos proclamados de simplificación y excelencia.

La estructura corporativa de Pemex, EPE

Tras la expropiación de 1938 y desde 1940, Pemex funcionó como una empresa petrolera integrada hasta que, a mediados de 1992, se dividió en un corporativo y cuatro organismos subsidiarios. ${ }^{18}$ En la ley de 1992 se conservó la calidad de Pemex como organismo público descentralizado, a cargo de "la conducción central y la dirección estratégica de todas las actividades que abarca la industria petrolera estatal" y se crearon cuatro "organismos descentralizados de carácter técnico, industrial y comercial".

La reforma constitucional en materia de energía de diciembre de 2013 estableció, en el párrafo séptimo del Art. 27, la figura de empresa productiva del Estado como el instrumento mediante el cual la Nación "llevará a cabo las actividades de exploración y extracción del petróleo y demás hidrocarburos" a través de asignaciones o contratos, en los términos de la ley reglamentaria. Ésta, por su parte, con el título de "Ley de Petróleos Mexicanos", 19 establece el marco legal en el que Pemex actuará en su carácter de epe, "de propiedad exclusiva del Gobierno Federal, con personalidad jurídica y patrimonio propios [, con] autonomía técnica, operativa y de gestión". Prevé asimismo que, para cumplir con su objeto, Pemex podrá apoyarse, inter alia, en "empresas productivas subsidiarias y empresas filiales" y delega en el Consejo de Administración de la EPE la facultad de dotar a Pemex de "la organización y estructura corporativa que mejor convenga para la realización de su objeto". Señala que ambas "deberán atender a la optimización de los recursos humanos, financieros y materiales; la simplificación de procesos; la eficiencia y la transparencia y la adopción de las mejores practicas corporativas y empresariales a nivel nacional e internacional, asegurando su autonomía técnica y de gestión".

Hay, evidentemente, una causación circular entre las autonomías técnica, operativa y de gestión. Deben ejercitarse las tres, para no anularse entre sí. El ejercicio de las tres depende, a su vez, de una cabal autonomía financiera y presupuestal. Hasta ahora, veinte meses después de la reforma constitucional, no están establecidas las condiciones para el ejercicio de las cinco autonomías. En diversos momentos, la autoridad hacendaria ha atentado contra las mismas. El ejemplo más evidente se

18 "Ley orgánica de Petróleos Mexicanos y organismos subsidiarios", Diario Oficial de la Federación, México, 16 de julio de 1992, pp. 30-35.

19 Véase "Ley de Petróleos Mexicanos", Diario Oficial de la Federación, México, 11 de agosto de 2014. 
encuentra en la imposición del primero de los recortes presupuestales, a fines de enero de 2015.20

De acuerdo con la Ley de Pemex, las empresas productivas subsidiarias se conciben como las directamente vinculadas a la exploración y extracción de hidrocarburos y se estipula que deberá tratarse de "empresas productivas del Estado, con personalidad jurídica y patrimonio propio". Su "creación, fusión o escisión... será autorizada por el Consejo de Administración de Petróleos Mexicanos, a propuesta de su Director General". El Consejo recibió, consideró y aprobó la propuesta del director general en su sesión 882 extraordinaria, de 18 de noviembre de 2014.

El Consejo, de acuerdo con el Acta relativa, ${ }^{21}$ acordó, inter alia, a) la transformación de Pemex-Exploración y Producción en la empresa productiva subsdiaria de Exploración y Producción"; b) la reorganización de Pemex-Refinación, Pemex-Gas y Petroquímica Básica y Pemex-Petroquímica en la empresa productiva subsidiaria Transformación Industrial; y, c) la creación de cinco empresas productivas subsidiarias para la integración de las funciones de (i) Perforación, (ii) Cogeneración y Servicios, (iii) Logística, (iv) Fertilizantes, y (v) Etileno, 22 en tanto se cumplen los supuestos legales para su transformación en empresas filiales. Además, el Consejo estableció dos plazos: 90 días naturales para conocer las propuestas de acuerdos de creación de las empresas productivas subsidiarias, y 120 días para conocer a) el esquema de precios, tarifas y asignaciones de costos aplicables en las transacciones comerciales entre Pemex y sus empresas productivas subsidiarias y filiales; $y, b$ ) la propuesta de lineamientos y estrategia para el manejo integral de las filiales de Pemex.

Tras una ampliación del primero de estos plazos, el Consejo realizó in extremis, es decir, el último día del nuevo plazo, una sesión extraordinaria cuyo orden del día

20 La prensa nacional informó el 30 de enero de 2015 del anuncio del secretario de Hacienda y Crédito Público de ajustar en 62 mil millones de pesos el presupuesto asignado a Pemex en 2015 (véase, por ejemplo, "Recorte quita a Pemex el equivalente de 41 días de presupuesto", El Financiero, México, 30 de enero de 2015 - http://www.elfinanciero.com.mx/economia/recortequita-a-Pemex-el-equivalente-a-41-dias-de-presupuesto.html) El Consejo de Administración de Pemex, "en su sesión del 13 de febrero aprobó el plan de ajuste presupuestal de 62 mil millones de pesos presentado por el director general de Pemex, lo que representa una disminución de 11.5 por ciento respecto al presupuesto programable autorizado por el Congreso de la Unión" (Pemex, "Ajuste al presupuesto 2015 de Petróleos Mexicanos", boletín nacional 11, 16 de febrero de 2015 - http://www.pemex.com/saladeprensa/boletines_nacionales/Paginas/2015-011-nacional.aspx). La autonomía presupuestal alcanza para distribuir una reducción de los recursos asignados a la EPE en el presupuesto aprobado por el Congreso pero no para definir el monto mismo del ajuste.

21 Véase "Consejo de Administración, Acta sesión 882 extraordinaria, 18 de noviembre de 2014" (www.pemex.org/acerca/gobierno-corporativo/consejo7Acuerdos\%202014/acta_882_ext.pdf, pp 13-23).

22 Pasar de cuatro a dos subsidiarias no fue un movimiento que reclamara gran cogitación. Que las EPE subsidiarias fuesen empresas del Estado sí fue asunto discutido. Se acudió entonces a la figura de empresas filiales, cuya naturaleza es por completo flexible y en las que pueden participar, incluso mayoritariamente, empresas privadas foráneas. Desempeñarán servicios esenciales para las EPE subsidiarias o para llevar adelante proyectos en ramas específicas. No se constituyeron directamente como filiales porque el marco legal y regulatorio aún no está completo. 
incluyó una nueva consideración del Estatuto Orgánico de Pemex y de las propuestas de acuerdos de creación de las empresas productivas subsidiarias. 23

En lo referente al Estatuto, el Consejo aprobó las modificaciones a la reorganización corporativa establecida en la sesión, antes referida, de 18 de noviembre de 2014.24 El Consejo también aprobó "el Estatuto Orgánico de Petróleos Mexicanos, con la modificación solicitada, en los términos del documento anexo". 25 El acta no es explícita respecto del alcance y contenido de tal modificación, pues se limita a consignar, respecto de este extremo, que uno de los consejeros independientes comentó que la transformación de Pemex en EPE "implicaba que tendría que planear y ejecutar sus actividades de manera más proactiva", por lo que sería necesario "modificar la normativa interna de manera dinámica, a fin de buscar una operación más ágil, acorde con los cambios del mercado y de la competencia”. En lo relativo a las empresas subsidiarias, también en la sesión de 27 de marzo, el Consejo aprobó los acuerdos de creación de las siete empresas productivas del Estado subsidiarias de Pemex ya mencionadas. 26

\section{El proceso de transición tras la reforma}

Al examinar la cuestión de los lapsos de transición establecidos en ley para implementar la reforma constitucional en materia energética, en lo que se refiere a la estructura corporativa reformada de Pemex, debe partirse del Art. Tercero Transitorio del decreto de reforma constitucional de 20 de diciembre de 2013.27 Se dispone que los diversos plazos que sea necesario establecer "no podrán exceder de dos años a partir de la publicación de este Decreto, para que los organismos descentralizados denominados Petróleos Mexicanos y Comisión Federal de Electricidad se conviertan en empresas productivas del Estado". Ese lapso, el límite constitucional para la conversión de Pemex en epe, vence el 19 de diciembre próximo.

De manera formal, Pemex se transformó por ministerio de ley en empresa productiva del Estado a la entrada en vigor de la Ley de Petróleos Mexicanos, promulgada el 11 de agosto de 2014. Esta entrada en vigor tuvo lugar al día siguiente de la desig-

23 Véase "Acta de la sesión 888 extraordinaria de 27 de marzo de 2015" (htpp://www.pemex.com/ acerca/gobierno-corporativo/consejo/Documents/acuerdos_2015/acta_888_ext_vp.pdf).

24 Véase "Acuerdo CA-015/2015 I.1 Estatuto Orgánico de Petróleos Mexicanos”, Consejo de Administración de Petróleos Mexicanos, Sesión 888 Extraordinaria, 27 de marzo de 2015. (htpp:// www.pemex.com/acerca/gobierno-corporativo/consejo/Documents/acuerdos_2015./sesion888_ext_vp.pdf).

25 Ibídem. Hubo de transcurrir un mes para que el texto del Estatuto Orgánico, aprobado el 27 de marzo, fuese publicado en el Diario Oficial de la Federación, el 28 de abril de 2015.

26 Véase "Acuerdo CA-016/2015 I.2 Acuerdos de Creación de Empresas Productivas Subsidiarias", Consejo de Administración de Petróleos Mexicanos, Sesión 888 Extraordinaria, 27 de marzo de 2015. (www.pemex.com/acerca/gobierno-corporativo/consejo/Documents/acuerdos_2015/ sesion888_ext_vp.pdf).

27 Véase "Decreto por el que se reforman y adicionan diversas disposiciones de la Constitución Política de los Estados Unidos Mexicanos, en Materia de Energía, Diario Oficial de la Federación, México, 20 de diciembre de 2013. 
nación del nuevo Consejo de Administración, hecho que ocurrió el 18 de septiembre, fecha en la que el Senado aprobó las designaciones de consejeros independientes hechas por el Ejecutivo. Empero, entre la conversión de jure y la transformación de facto, es decir, la plena operación de Pemex como EPE, transcurre un período de transición que aún no termina.

El nuevo Estatuto Orgánico entró en vigor el 29 de abril de 2015, día siguiente al de su publicación en el DOF.

En su sesión extraordinaria 881, de 7 de noviembre de 2014, el Consejo adoptó acuerdos, aplicables a Pemex, sus empresas productivas subsidiarias y filiales, y relacionados con: 28

- Las políticas para la contratación por Pemex de seguros, fianzas o cauciones a favor de directores y funcionarios, que comprenderán, al menos, (i) el monto de la indemnización por los daños que cause su actuación y (ii) los servicios de defensa y asistencia legal de cualquier procedimiento, judicial o administrativo, en el que se les reclame responsabilidad civil, penal, administrativa o de cualquier otra índole, con motivo del desempeño o del ejercicio de sus funciones. Se ha hecho notar que una disposición de este tipo elimina, o cuando menos vulnera, la intención disuasiva del régimen de responsabilidades de los funcionarios de Pemex y empresas subsidiarias.

- Las políticas para la revelación, resguardo y protección de la información.

- Los lineamientos que regulan el sistema de control interno, los aplicables en materia de auditoría y los referidos a la evaluación del desempeño.

- Los mecanismos de coordinación entre la Unidad de Responsabilidades y la Auditoría Interna.

- La emisión de un Código de Ética de obligatorio cumplimiento por todo el personal, "a todo nivel, en toda actividad y en todo momento", así como un Comité de Ética, presidido por el director corporativo de Administración e integrado por representantes de las direcciones corporativas, de las empresas productivas subsidiarias y de las empresas filiales, el subdirector de Recursos Humanos y Relaciones Laborales y un representante de la Unidad de Control Interno Institucional.

Como muestran los puntos anteriores, Pemex se ha dotado de un sistema por completo auto referenciado, una clara muestra de autorregulación. La experiencia internacional de los años recientes, tanto en corporaciones petroleras como financieras, ha demostrado que este tipo de enfoques de autorregulación por lo general no funcionan. Tras la aprobación de estos siete instrumentos, el Consejo acordó solicitar a la Secretaría de Energía que "emita la declaratoria de que se encuentran en operación los mecanismos de fiscalización, transparencia y rendición de cuentas previstos en la Ley".

28 Véase Consejo de Administración de Petróleos Mexicanos, Sesión 881 Extraordinaria, "Acuerdos CA-115/2014, CA-116/2014, CA-117/2014, CA-118/2014, CA-119/2014, CA-120/2014, CA121/2014, CA-122/2014 y CA-123/2014", 7 de noviembre de 2014 (www.pemex.com/acerca/ gobierno-corporativo /consejo/Acuerdos\%202014/sesion881_extraordinaria.pdf). 
En suma, a lo largo de 2014 y 2015 Pemex ha vivido un largo período de transición en tiempo presente, que no es congruente con los objetivos de funcionalidad y eficiencia proclamados en la reforma.

\section{Cuestiones laborales}

La Ley de Petróleos Mexicanos, promulgada el 11 de agosto de 2014, otorgó a Pemex, EPE, el plazo de un año para alcanzar un acuerdo con el STPRM, a fin de modificar el contrato colectivo de trabajo en lo correspondiente al pago de las obligaciones contraídas por la empresa y organismos subsidiarios respecto a las pensiones y jubilaciones con sus trabajadores. Análogo plazo de contempla para modificar el Reglamento de Trabajo del Personal de Confianza. El acuerdo entre el sindicato y la empresa en materia de pensiones y jubilaciones es condición impuesta por la Secretaría de Hacienda y Crédito Público para absorber una parte -incierta- del pasivo laboral.

La Auditoría Superior de la Federación concluyó oportunamente sus trabajos conducentes a determinar el monto del pasivo laboral de la empresa. Arribó a la conclusión de que el número de trabajadores jubilados y beneficiarios post-mortem representa $81.7 \%$ de los trabajadores en activo y que el monto de las obligaciones asumidas asciende a 1473 mil millones de pesos. En observancia de las normas laborales vigentes, el stprm emplazó a huelga a Pemex, epe, con objeto de proceder a la revisión bianual del contrato colectivo de trabajo. Esa revisión sería la ocasión propicia para revisar los alcances de las obligaciones de la empresa en materia de jubilaciones y pensiones.

Ante la falta de acuerdos, el pasado 8 de agosto de 2015, ambas partes convinieron en ampliar en un mes el plazo para concluir las negociaciones, lo cual ilustra las enormes dificultades políticas y económicas que entraña la revisión a fondo de un contrato cuyo texto es muy extenso y complejo. Además, son todavía desconocidas las condiciones contractuales que se establecerán entra las empresas privadas que iniciarán funciones en la industria petrolera y el stprm, a toda vez que la Secretaría del Trabajo y Previsión Social reconoció a éste el carácter de "sindicato de rama" productiva.

\section{Resultados esperados e implicaciones para el desarrollo}

\section{La apertura en exploración y extracción de hidrocarburos}

Más allá de la transformación de la estructura organizativa y operacional de Pemex, examinada en el apartado anterior, este último alude a uno de los aspectos centrales de la reforma energética, la apertura del subsector petrolero, es decir, la renuncia del Estado a la exclusividad en las funciones de exploración y extracción y el estrechamiento del ámbito de propiedad de la Nación sobre los hidrocarburos. 
Aunque la apertura abarca a la totalidad de la industria, incluyendo refinación, proceso del gas y almacenamiento, transporte y distribución de petrolíferos y gas, la implementación de estos aspectos apenas se inicia. De esta suerte, el análisis se limita a las primeras acciones para emprender la apertura en las actividades aguas arriba.

Para ponerla en práctica, se procedió, en primer término, a asignar a Pemex campos petroleros y áreas en que, cumpliendo requisitos de oportunidad y eficiencia, podrá continuar realizando actividades de exploración y extracción. Hecho esto, se decidió acudir a la licitación abierta de otros campos y áreas, tanto en tierra como costa afuera, para la realización de esas tareas por parte de empresas privadas, nacionales o foráneas, y por Pemex, por sí mismo o asociado con terceros.

\section{Ronda Cero: nueva base productiva de Pemex}

El proceso de adjudicar las asignaciones, coloquialmente denominado por las autoridades Ronda Cero, concluyó en agosto de 2014 con la asignación a Pemex de 489 campos en producción (de los 768 registrados por la empresa en esa fecha), con un contenido estimado de reservas $2 \mathrm{P}$ de 20589 millones de barriles (83\% del total nacional). Como parte de la misma Ronda Cero le fueron asignadas 72897 km$^{2}$ de áreas para la exploración, con un contenido estimado de recursos prospectivos por descubrir de 23447 millones de barriles (21\% del estimado nacional).

Los 489 campos asignados a Pemex comprenden 286 para realizar actividades de extracción, 108 de exploración y 95 de ellos, según se dio a conocer meses después de la asignación, fueron asignados en resguardo temporal por dos años o hasta que sean subastados por el Estado en rondas de licitaciones. En los campos asignados se localiza el total de las reservas probadas nacionales registradas al inicio 2014, esto es, 13438 millones de barriles de petróleo crudo equivalente. Un año después, al inicio de 2015, los derechos de extracción de reservas probadas de Pemex se limitaron a 12047 millones de barriles (equivalen a un mínimo histórico de 9.3 años de extracción). La diferencia se explica porque la restitución de reservas en 2014 fue inferior a la extracción de ese año y porque además 977 millones de barriles de las reservas probadas corresponden a los 95 campos sobre los que Pemex tiene asignados en resguardo temporal.

La expectativa de la sener sobre los resultado de la Ronda Cero es que la asignación a Pemex de reservas probadas y posibles permitirá a la empresa mantener una producción de 2.5 millones de barriles diarios de petróleo crudo, a lo largo de diez años y medio años, y de otros cinco años adicionales con la asignación de los recursos prospectivos. Sus cálculos no recogen el impacto de la menor restitución de 2014 ni el hecho de los 95 campos de resguardo temporal. La meta nacional de la reforma energética es extraer 3 millones de barriles diarios en 2018 y 3.5 millones en 2025. La diferencia entre estas metas y lo que suministraría Pemex tendría que ser cubierta por empresas beneficiarias de la adjudicación de contratos, lo cual es difícil que ocurra en períodos tan breves. Respecto al gas esas diferencias son aún más ambiciosas, lo mismo que el objetivo de restituir las reservas en al menos 100 por ciento. 
La SENER no ofrece elementos de juicio que fundamenten la posibilidad de concretar las expectativas de producción respecto a la asignaciones y los contratos, particularmente en lo que hace a la extracción y restitución de reservas y la viabilidad de explotar los recursos prospectivos. En todo caso, se refuerza el imperativo de asegurar que Pemex pueda disponer de los recursos financieros y de otra índole necesarios para la ejecución de los planes y programas de extracción y exploración comprometidos en las asignaciones y que la reacción de las empresas privadas sea favorable a la subasta de campos y áreas que se propone realizar el Estado.

En las asignaciones de áreas de exploración, Pemex deberá cumplir planes de trabajos e inversiones para cada una de las áreas asignadas, en un plazo de tres años, prorrogable por un máximo adicional de dos. De no cumplirse con el plan, las áreas asignadas se revertirán al Estado.

Respecto a las asignaciones de extracción se otorgan a Pemex los derechos de producción, para lo cual deberá cumplir planes de desarrollo de los campos asignados, con descripción de trabajos e inversiones que justifiquen su aprovechamiento eficiente y competitivo.

El cumplimiento de dichos planes es fundamental para alcanzar las metas de la reforma energética de 2018 y 2025. De mayor trascendencia es sin embargo el impacto de un eventual incumplimiento de los planes de Pemex sobre la recaudación fiscal, las cuentas con el exterior y el mercado de divisas. El impacto se amplifica ante la prolongada reducción de los precios internacionales del petróleo cuya perspectiva es incierta en los próximo meses y años.

No es público el detalle o la información agregada de los planes de exploración y desarrollo de campos en producción y de las, inversiones para ello requeridas o información que ilustre sobre su contenido. Tampoco se dispone de información sobre su la incidencia de estas inversiones en el presupuesto de Pemex. Su conocimiento es vital para ponderar las consecuencias de reducciones presupuestales, como la ya mencionada de principios de año, y para la elaboración del presupuesto del próximo año y los siguientes.

La permanencia e incertidumbre de precios bajos en la cotización internacional del petróleo impacta en la recaudación fiscal, a lo cual se suma la dificultad de mantener los niveles programados de extracción. En la medida que ambas circunstancias derivan en reducciones o recortes del presupuesto de Pemex, se amplifican las consecuencias adversas en los planes de exploración y desarrollo para el sostenimiento de dichos niveles de extracción. Por ello resulta aconsejable evaluar alternativas para enfrentar la baja de precios del crudo y la caída de la producción.

La modificación constitucional en materia energética de 2013 ofrece a posibilidad de que Pemex pueda migrar áreas y campos asignados al régimen de contratos, previa solicitud que deberá autorizar la sener -con la asistencia técnica de la cnh-, y que se cumpla con el proceso licitatorio que establece la legislación para la adjudicación de contratos de extracción y exploración.

Cuando se publicitó en los medios informativos la decisión de la sener sobre la Ronda Cero en agosto de 2014, se hizo público que Pemex solicitaría convertir al ré- 
gimen de contratos dos tipos de asignaciones. Las primeras, que involucran contratos vigentes previamente suscritos por la empresa con particulares: copf's o de Obra Pública Financiada y ciep's o Integrales de Exploración y Producción. Las segundas se refieren a la subcontratación, coinversiones o asociaciones denominados farmouts, para campos petroleros asignados con reservas 2P.

En marzo de 2015 se informó que Pemex había presentado a la sener solicitudes de migración de 9 contratos copf's y ciep's y de 14 farm-outs. Las solicitudes involucran alrededor de 4,200 millones de barriles de petróleo crudo equivalente de reservas 3P. No se conoce aún la resolución de la sener sobre el resultado de dichas solicitudes.

Pemex podría obtener ventajas fiscales y financieras al migrar sus asignaciones al régimen de contratos. Estas ventajas se amplifican en virtud de la astringencia de recursos de que dispone para cumplir con los planes y programas de sus asignaciones.

No obstante, para el gobierno federal el impacto de las migraciones es distinto. Las contraprestaciones e impuestos a cargo de los contratistas particulares son inferiores a los derechos e impuestos que Pemex está obligado a pagar. No hay bases sólidas para suponer que las supuestas ventajas de eficiencia de las empresas privadas puedan compensar las diferencias en la generación de ingresos fiscales entre ambas formas de aprovechar el patrimonio nacional.

El artículo 27 de la Constitución, con las modificaciones en materia energética decretadas en diciembre de 2013, establece que las actividades de exploración y extracción de hidrocarburos se llevarán a cabo mediante asignaciones a epe's o a través de contratos con particulares. Los artículos transitorios cuarto y sexto del Decreto mencionado que contiene esas enmiendas señalan las modalidades de contratación y los términos de adjudicar las asignaciones, respectivamente.

Respecto a estas últimas se establece que a petición de Pemex, la SENER, con la asistencia técnica de la $\mathrm{CNH}$, emitirá la resolución correspondiente sobre las asignaciones autorizadas. La disposición involucra tomar decisiones sobre el patrimonio nacional, sin embargo, no por ello se previó una regulación específica para cumplir el mandato constitucional, ni mecanismo alguno de consulta o participación del Poder Legislativo u otro órganos del Estado en la decisión. De hecho, por mayoría, el Consejo de Administración de Pemex, decidió delegar en su Comité de Estrategia e Inversiones (CEI), la integración de la lista de campos petroleros y áreas exploratorias a solicitar a la SENER.

Quizá el haber delegado al CEI una decisión de esta trascendencia para el futuro de la empresa o el hecho de que la solicitud planteada haya sido parcialmente denegada por la SENER sea lo que explica un hecho por lo menos inesperado: el 6 de agosto de 2015, el Consejo de Administración tomó conocimiento de que la empresa había presentado una solicitud y una propuesta a la SENER. 29

La solicitud alude "a obtener recursos prospectivos adicionales a los asignados en la Ronda Cero, a efecto de fortalecer el portafolio de exploración en el mediano y largo

29 Véase Consejo de Administración de Petróleos Mexicanos, Sesión 897 Extraordinaria, Acuerdo CA-166/2015, 6 de agosto de 2015 (http://www.pemex.com/acerca/gobierno-corporativo/consejo/ Documents/acuerdos_2015/sesion_897_ext.pdf.). 
plazo, correspondientes a: i) un área adicional en aguas profundas y ii) la asignación de derechos de exploración en cinco asignaciones en la Cuenca Tampico-Misantla".

La propuesta se refiere a modificar las asignaciones que actualmente tiene $\mathrm{Pe}$ mex, a fin de "mantener el balance general de los recursos prospectivos otorgados en Ronda Cero, dando preferencia a los campos del Estado que no cuentan con derechos de exploración".

No es viable, con la información pública disponible, juzgar la importancia o alcance de estas acciones de Pemex. No se divulgaron precisiones de la solicitud inicial de la empresa, tampoco hubo detalles de la respuesta de las autoridades respecto a los planes y programas autorizados para los campos y áreas asignados. Ahora, sólo se hace público el texto del acuerdo del Consejo pero no la información que permita apreciar la trascendencia de la nueva solicitud.

Un componente de la reforma constitucional en materia de energía completamente olvidado, hasta ahora por lo menos, es el contenido en el quinto párrafo del artículo sexto transitorio del decreto constitucional. Esta disposición señala que, si como resultado de dicho proceso "se llegaran a afectar inversiones de Petróleos Mexicanos, éstas serán reconocidas en su justo valor económico", que determinará la sener. Pemex debió haber informado a la sener de las afectaciones derivadas del proceso de asignaciones pero no ha habido noticia de que se hayan adoptado providencias para determinar su valor económico y las compensaciones correspondientes. Más aún, en diversos foros públicos y en el Congreso mismo, las autoridades no han informado a la Nación sobre el estado que guarda el cumplimiento del mandato constitucional.

\section{Licitaciones: subasta del acceso al patrimonio petrolero}

La Constitución y la legislación reglamentaria de las modificaciones constitucionales de diciembre de 2013 en materia de energía, establecen que mediante rondas internacionales de licitaciones públicas, el Estado llevará a cabo la suscripción de contratos con particulares en las actividades de exploración y extracción en las siguientes modalidades, entre otras: contratos de servicio, de utilidad o producción compartida $y$ de licencia u otros.

El Plan Quinquenal de Licitaciones para la Exploración y Extracción de Hidrocarburos 2015-2019 presentado por la sener con carácter preliminar en junio de 2015, a partir de la propuesta técnica entregada por la cnh el 30 de abril de 2015 -cuando ya se habían anunciado y habían empezado a organizarse las primeras licitaciones-, incluye la identificación de los campos petroleros para la extracción de hidrocarburos y las áreas para exploración de recursos prospectivos convencionales y no convencionales, que serán materia de licitación en cuatro rondas sucesivas.

El Plan propone subastar 244 campos petroleros para extraer recursos remanentes 3P estimados en 68205 millones de barriles (cuadro 16). La sener también se refiere a esos recursos con las denominaciones de recurso original remanente 3P, volumen remanente de hidrocarburos, volumen remanente o volumen original remanente y los define como la diferencia aritmética entre el volumen original y el producido. 


\begin{tabular}{|c|c|c|c|c|c|c|}
\hline \multicolumn{7}{|l|}{ Cuadro 16} \\
\hline \multicolumn{7}{|c|}{$\begin{array}{l}\text { Licitaciones para extracción Recurso original remanente 3P } \\
\text { (miles de millones de barriles de petróleo crudo equivalente) }\end{array}$} \\
\hline Rondas de licitación & Total & $\begin{array}{l}\text { Aguas } \\
\text { someras }\end{array}$ & $\begin{array}{c}\text { Aguas } \\
\text { profundas }\end{array}$ & $\begin{array}{l}\text { Marino extra } \\
\text { pesados }\end{array}$ & Chicontepec & Terrestres \\
\hline Plan quinquenal & 68.2 & 4.7 & 0.5 & 16.7 & 42.2 & 4.1 \\
\hline Ronda uno & 63.2 & 3.2 & & 16.0 & 42.2 & 1.8 \\
\hline Convocatoria $2^{*}$ & 3.2 & 3.2 & & & & \\
\hline Convocatoria 3 & 1.8 & & & & & 1.8 \\
\hline Otras convocatorias & 58.2 & & & 16.0 & 42.2 & \\
\hline Ronda dos & 3.5 & 0.6 & 0.5 & 0.7 & & 1.7 \\
\hline Ronda tres & 1.2 & 0.9 & & & & 0.3 \\
\hline Ronda cuatro & 0.3 & & & & & 0.3 \\
\hline
\end{tabular}

${ }^{*}$ Campos de extracción con reservas (mmmbpce): 1P 0.143, 2P 0.355 y 3P 0.671 Fuente: elaboración propia con información de Secretaría de Energía: Plan Quinquenal de Licitaciones para la Exploración y Extracción de Hidrocarburos $2015-2019$.

Adviértase que los recursos remanentes 3P ubicados en Chicontepec (42 200 millones de barriles) constituyen $62 \%$ de los considerados en el Plan Quinquenal para fines de extracción y que se propone licitarlos todos ellos en la Ronda Uno. Sobre esta cuenca la cnh señala lo siguiente: [...] Los proyectos de Chicontepec presentan bajos niveles de rentabilidad y elevada incertidumbre respecto al total de proyectos, no sólo respecto a los proyectos de explotación. $100 \%$ de los proyectos en Chicontepec se encuentra en el grupo de menor rentabilidad y mayor incertidumbre. 30

Otro $24.5 \%$ de los recursos remanentes 3P corresponde a crudos extra pesados marinos y también se propone subastarlos casi todos en la Ronda Uno. Estos recursos, presumiblemente situados en una zona de transición entre aguas someras y profundas, reclaman para su extracción de inversiones mayores y tecnologías más avanzadas que las correspondientes a crudos convencionales de aguas someras. Las expectativas de explotación son promisoras, si se logran aplicar tecnologías de vanguardia para el manejo en campo de este tipo de hidrocarburos y si la cotización internacional del petróleo hace factible la utilización de las mismas.

El restante $13.5 \%$ de los recursos remanentes $3 \mathrm{P}$ se sitúan en aguas someras y profundas y en campos terrestres convencionales y serán licitados en su mayor parte en las Rondas subsecuentes a la Uno.

Respecto a la subasta para exploración petrolera, el Plan Quinquenal señala, en su versión de junio de 2015, que serán licitados 137 mil km² y 34 mil km², en áreas que se estima alojan en el subsuelo 14.6 mil millones de barriles de recursos prospectivos convencionales por descubrir y 24.6 mil millones de recursos no convencionales, respectivamente. La suma de ambos volúmenes asciende a 39.3 mil millones de barriles (cuadros 17).

30 Veáse CNH, Clasificación de los proyectos de exploración y explotación de hidrocarburos: Estadísticas de rentabilidad e incertidumbre, Documento Técnico de Trabajo-3 (www.cnh.gob. $\mathrm{mx} /$ docs/DT3.pdf). 


\begin{tabular}{|c|c|c|c|c|c|}
\hline \multicolumn{6}{|l|}{ Cuadro 17} \\
\hline \multicolumn{6}{|c|}{$\begin{array}{l}\text { Licitaciones para exploración de recursos convencionales y no convencionales Recursos pros- } \\
\text { pectivos por descubrir (miles de millones de barriles de petróleo crudo equivalente) }\end{array}$} \\
\hline \multirow[b]{2}{*}{ Rondas de licitación } & \multicolumn{4}{|c|}{ Convencionales } & \multirow{2}{*}{$\begin{array}{c}\text { No } \\
\text { convencionales } \\
\text { (terrestres) }\end{array}$} \\
\hline & Total & $\begin{array}{l}\text { Aguas } \\
\text { someras }\end{array}$ & $\begin{array}{c}\text { Aguas } \\
\text { profundas }\end{array}$ & Terrestres & \\
\hline Plan quinquenal & 14.6 & 3.5 & 9.7 & 1.4 & 24.6 \\
\hline Ronda uno & 1.4 & 0.7 & 0.7 & & 7.4 \\
\hline Convocatoria 1 & 0.7 & 0.7 & & & \\
\hline Otras & 0.7 & & 0.7 & & 7.4 \\
\hline Ronda dos & 5.1 & 1.3 & 3.3 & 0.5 & 7.0 \\
\hline Ronda tres & 4.9 & 0.9 & 3.5 & 0.5 & 6.6 \\
\hline Ronda cuatro & 3.2 & 0.6 & 2.3 & 0.3 & 3.5 \\
\hline
\end{tabular}

Fuente: elaboración propia con información de Secretaría de Energía: Plan Quinquenal de Licitaciones para la Exploración y Extracción de Hidrocarburos 2015-2019 SENER, junio 30, 2015.

En lo que hace a las licitaciones para explorar áreas con recursos convencionales, dos terceras partes se localizan en aguas profundas, $24 \%$ en aguas someras y casi $10 \%$ en superficie terrestre. Más de $90 \%$ de todos estos recursos será materia de licitación en las Rondas subsiguientes a la Uno.

La subasta de áreas para explorar recursos prospectivos no convencionales comprenden en su mayoría yacimientos terrestres en formaciones geológicas de lutitas (shale). Son conocidos y cuestionables los riesgos ambientales que supone la explotación de este tipo de recursos, entre ellos contaminación de suelos, consumo de agua y afectación de acuíferos y emisiones de metano, entre otros. Sería importante una evaluación cuidadosa, que incluya los impactos regionales de estos riesgos como parte de la información básica para fundamentar y conducir los procesos licitatorios. El Plan Quinquenal prevé que estas áreas serán materia de licitación en las cuatro Rondas.

\section{Ronda Uno: las tres primeras convocatorias}

La Ronda Uno inició el proceso de licitaciones, ahora en curso, mediante tres convocatorias que fueron publicadas sucesivamente el 11 de diciembre de 2014, el 27 de febrero y el 12 de mayo de 2015.

La primera de las convocatorias, en la modalidad de contratos de producción compartida, comprendió 14 bloques, en una superficie de 4.2 mil km² de aguas someras, con recursos prospectivos convencionales estimados en 0.7 mil millones de barriles de petróleo crudo equivalente ( $20 \%$ del volumen en aguas someras a licitar en las cuatro Rondas). Sólo dos de los 14 bloques fueron adjudicados al mismo consorcio que en ambos casos presentó la mejor oferta. Los contratos se encuentran en proceso de suscripción. 
Conforme a los resultados del concurso de esta primera convocatoria, el Estado tendrá derecho a participar en 56 y $69 \%$ de la utilidad operativa de los dos contratos. Con estas participaciones el licitante ganador superó sustancialmente los valores mínimos de adjudicación establecidos por la SHCP (40\%), mismos que fueron del conocimiento público hasta el momento de apertura de las posturas de las empresas concursantes. La magnitud de esas diferencias, entre otros indicadores, puso de manifiesto que [...] "la SHCP estableció condiciones muy generosas para las empresas o consorcios interesados en participar en la primera convocatoria de la Ronda Uno" [...], a pesar de lo cual solo fue posible suscribir contratos para 2 de los 14 bloques en subasta. 31

La contraprestación que finalmente reciba el Estado, correspondiente a estos dos contratos, dependerá del volumen efectivo de extracción, la cotización internacional que alcancen los hidrocarburos y la recuperación de costos que acredite el contratista. Analistas y empresas de consultoría han formulado estimaciones sobre la posible magnitud de estas variables. Un ejercicio numérico simple permite concluir que con un precio del barril de petróleo de 50 dólares y una recuperación de costos del contratista de $60 \%$ del valor de los hidrocarburos -cifra contractual máxima-, la utilidad operativa a distribuir, una vez deducido el valor de la regalía, sería del orden de $35 \%$ del valor de los hidrocarburos (se asume un impacto marginal del mecanismo de ajuste por riesgo exploratorio). Al gobierno correspondería el $56 \%$ de esa utilidad, en uno de los contratos, y $69 \%$ en el otro.

En suma, la contraprestación a favor del gobierno integrada por la utilidad compartida, la regalía y el impuesto sobre la renta, con los supuestos referidos, se situaría entre 30 y $35 \%$ del valor de los hidrocarburos. Estas proporciones equivalen a la mitad de los ingresos que Pemex entera al fisco por concepto de derechos y otros cargos. Otros supuestos menos severos conducirían a estimaciones de mayor dimensión. No obstante, es posible concluir que la participación del gobierno en la renta petrolera resultante de esta licitación dista considerablemente de la que arroja el régimen fiscal de asignaciones. Baste citar que con este régimen la máxima recuperación de costos que tiene derecho a acreditar es inferior a $12 \%$ del valor de los hidrocarburos, en contraste con $60 \%$ admisible en el de contratos.

La segunda convocatoria de la Ronda Uno, también en la modalidad de producción compartida, es para la extracción de hidrocarburos situados en campos de aguas someras, con recursos remanentes 3P calculados en 3.2 mil millones de barri-

31 Víctor Rodríguez Padilla, profesor e investigador de la UNAM calcula que los ingresos del gobierno, derivados de los dos bloques adjudicados, equivaldrán a una proporción de $20.7 \%$ de la utilidad operativa que eventualmente obtengan los contratistas. Esta cifra es apenas una fracción de las participaciones superiores a $60 \%$ que han mencionado diversas autoridades. El investigador estima que, con un precio de Dls. 50 por barril, "el consorcio privado, de tener éxito, obtendría una utilidad conjunta [en ambos bloques], sumando el límite de recuperación de costos, de 79.3\%". La inversión total prevista sería cercana a Dls. 2600 millones y el consorcio aplicaría al máximo el límite de recuperación de costos, que llega a $60 \%$ del valor de los hidrocarburos (véase, Israel Rodríguez, "El Estado obtendría sólo 20.7\% de utilidad en los 2 bloques adjudicados en la primera subasta", La Jornada, México, 17 de agosto de 2012 - www.jornada.unam. mx/2015/ 08/18/economía/027n2eco). 
les (más de dos terceras partes de los recursos remanentes para extracción en aguas someras incluidos en el Plan Quinquenal).

La tercera convocatoria de la Ronda Uno, a diferencia de las dos anteriores, es bajo el régimen jurídico de contratos de licencia. Incluye 25 campos terrestres para extraer un estimado de 1.8 miles de millones de recursos remanentes 3P. Aparentemente casi todos se encuentren actualmente en producción.

\section{Zonas de salvaguardia: un precepto olvidado}

Un concepto importante, en términos del objetivo de seguridad energética de la Nación, que ha estado ausente por completo de las acciones o anuncios relacionados con la puesta en marcha de la reforma energética en el relativo a las zonas de salvaguardia. El artículo 41 de la Ley de Hidrocarburos estatuye que: "El Ejecutivo Federal, a propuesta de la Secretaría de Energía, establecerá Zonas de Salvaguardia en las áreas de reserva en las que el Estado determine prohibir las actividades de Exploración y Extracción de Hidrocarburos. La incorporación de áreas específicas a las zonas de salvaguardia y su desincorporación de las mismas será hecha por decreto presidencial fundado en los dictámenes técnicos respectivos." 32 Se dispone también que el dictamen técnico de la sener sobre el establecimiento de zonas de salvaguardia-dictado en atención a los intereses nacionales, incluyendo los de seguridad energética, sustentabilidad de la plataforma anual de extracción de hidrocarburos y la diversificación de mercados- deberá contar con la opinión favorable de la shcp.

Se requiere reparar la omisión en que hasta ahora se ha incurrido al descuidar la delimitación de esas zonas o, al menos, de informar por qué no es conveniente establecerlas. Sería también deseable que se previese la participación del Congreso en la delimitación y manejo de las zonas de salvaguardia, especie de reserva nacional de hidrocarburos, sustraídos al juego mercantil, que permita cumplir con intereses nacionales tan importantes como los señalados.

\section{Una perspectiva difícil para el desarrollo}

En los años de reforma hasta ahora transcurridos, 2014 y la primera mitad de 2015, los resultados operativos de Pemex no han sido satisfactorios. El primero de estos años marcó un mínimo en dos y medio decenios en el volumen de producción de petróleo crudo y gas natural, a lo que hay que agregar las caídas adicionales de 8.2 y $1.3 \%$ en enero-julio de 2015 , frente al mismo período del año inmediato anterior. La media diaria de producción de petrolíferos en ese año fue también la menor desde 1990, con excepción de 2011. La utilidad antes de impuestos y derechos fue la más baja desde 2006, sin contar la de 2009. En la primera mitad de 2015, esa utilidad representó apenas una fracción (3.2\%) de la cifra muy deprimida registrada el año previo. Numerosos factores explican estos deplorables resultados operativos y con-

32 Véase, "Decreto por el que se expide la Ley de Hidrocarburos y se reforman diversas disposiciones de la Ley de Inversión Extranjera; Ley Minera; y, Ley de Asociaciones Público Privadas", Diario Oficial de la Federación, México, 11 de agosto de 2014. 
tables, entre ellos, desde luego, el desplome de los precios internacionales del crudo. Parece probable, sin embargo, que el largo lapso de transición en tiempo presente, para establecer la nueva estructura organizacional y operativa de la empresa desde principios de 2014 , con su cauda de incertidumbres y fricciones políticas, ha influido también en estos resultados.

El sistema energético nacional, que operó desde principios de la década de 1980, mostró, en este siglo, sobre todo en los últimos dos lustros y, en particular, en 2014, síntomas evidentes de insuficiencia para seguir operando con el dinamismo del pasado. La reforma energética fue la fórmula planteada por los poderes ejecutivo y legislativo para responder a la creciente disfuncionalidad del sistema energético nacional. No constituía, desde luego, la única posible y cabía imaginar otras que sirvieran mejor a la preservación de los recursos, la seguridad energética de la Nación y el desarrollo del país.

La reforma energética que se aprobó no resuelve sino que más bien agrava tres características que resultaba indispensable alterar. No ofrece una salida efectiva a la concentración extremada en los hidrocarburos que se aprecia tradicionalmente en la oferta mexicana de energía. Por el contrario, al perseguir los mayores aumentos posibles en la extracción de petróleo y gas en campos maduros o abandonados, incluidos los provenientes de áreas hasta ahora no abiertas a la explotación, como los recursos marinos en aguas profundas, y los yacimientos no convencionales, aumentará la ponderación de éstos en la oferta total.

Priorizar la producción primaria de hidrocarburos, más que su transformación industrial, amenaza con mantener -por lo menos en los próximos diez años- la insuficiencia dinámica de la oferta de petrolíferos, en especial gasolinas, y gas natural; las consecuentes importaciones de éstos y el saldo negativo de la balanza comercial del sector.

En tercer lugar, la reforma refuerza el sesgo exportador de crudo y el sesgo importador de gas natural y derivados industriales de los hidrocarburos, pues las inversiones en extracción que promueve tendrán como destino preferente los mercados externos y las inversiones en infraestructura que alienta se orientarán a propiciar la importación de gas natural, petrolíferos, y productos petroquímicos Si se quisiera elegir un símil externo, la reforma se orienta a construir un sector petrolero como el de Nigeria y no como el de Noruega.

La carga fiscal de Pemex, ahora en calidad de epe, como antes de organismo público descentralizado, sigue siendo sumamente gravosa, no sólo en términos de los resultados de operación y de la solvencia económica y financiera requerida, sino también en comparación con las principales empresas internacionales y entidades estatales en su ramo. No hay elementos que permitan presagiar que, en lo que resta de la actual administración, se logrará reducir en forma importante la dependencia de las finanzas públicas respecto de los ingresos generados por Pemex, aunque la importancia relativa de éstos pueda disminuir por la caída de la producción y de los precios. 
La transformación de Pemex en EPE se ha cumplido en los aspectos legales y reglamentarios, pero la transición operativa tomará aún un período que puede abarcar la mayor parte del próximo trienio, además de alejarla del objetivo de fortalecerla y hacerla más competitiva y eficiente, por no referirse a la inminencia de la quiebra. Esta transformación ha afectado a sus órganos de gobierno, a su estructura orgánica y a su modelo de negocios. La reforma constitucional estableció un plazo de dos años para la transición, que concluye en diciembre de 2015.

No es suficientemente transparente la operación del nuevo Consejo de Administración de Pemex. Por lo que dejan ver las actas de sus sesiones que se han publicado hay deficiencias formales de operación de consecuencias potencialmente graves y se crea la impresión de que los asuntos que avala el Consejo son realmente discutidos y decididos en instancias distintas a sus reuniones formales.

La nueva estructura del corporativo de Pemex se expresa en una pirámide cuya base la integran cerca de 130 mil trabajadores activos y algo más de 85 mil jubilados y en cuyos estratos superiores se ubican 188 gerencias (frente a 97 anteriormente), 57 subdirecciones (frente a 23), 13 direcciones corporativas o equivalentes (frente a 8) y una dirección general (igual que antes). Si en la estructura corporativa de las subsidiarias se establecen estructuras paralelas en los diversos ámbitos se estará ampliando también el enorme potencial de traslapes y duplicaciones que no se corrigió, sino se agravó. La estructura orgánica básica de la empresa no parece cumplir los objetivos proclamados de simplificación y excelencia.

No se han ofrecido informaciones y elementos de juicio que fundamenten la posibilidad de que, con los campos petroleros que se le asignaron en la llamada Ronda Cero, Pemex pueda concretar las expectativas proclamadas, particularmente en lo que hace al aprovechamiento de las reservas probables y la restitución de las probadas. Tampoco se ha hecho lo propio respecto a las áreas que le fueron asignadas para la exploración de hidrocarburos. Es claro el imperativo de asegurar que Pemex pueda disponer de los recursos financieros y de otra índole necesarios para cumplir los planes y programas en campos y áreas que le fueron autorizados y que ni siquiera son de dominio público. De su cumplimiento depende alcanzar las metas nacionales cuantitativas que se establecieron para 2018 y 2025 y los resultados de desempeño del sector energético, al menos en el horizonte de los próximos quince años.

De mayor trascendencia aún es el impacto de un eventual incumplimiento de los planes y programas de Pemex sobre la recaudación fiscal, las cuentas con el exterior y el mercado de divisas. Este impacto se amplifica ante la prolongada reducción de los precios internacionales del petróleo cuya perspectiva es incierta en los próximos meses y años.

Con el anuncio del Plan Quinquenal de Licitaciones para la Exploración y Extracción de Hidrocarburos 2015-2019 queda en claro que los yacimientos cuya exploración se abre a los particulares, en cuatro rondas de licitación, son, sobre todo, los de aguas profundas y los no convencionales (lutitas). En cuanto a extracción, se trata mayormente de recursos remanentes en campos terrestres y marinos, con predominio de aceite extra pesado, además del paleocanal de Chicontepec. 
En el debate alrededor de la reforma energética se plantearon cuestiones como las siguientes. El cambio de paradigma que encierra la reforma energética tiene como esencia la apertura jurídica e institucional, casi irrestricta, a la inversión privada; el repliegue en las funciones reservadas en exclusividad al Estado y la reducción del ámbito de soberanía de la Nación sobre los hidrocarburos. Parece darse por hecho que la reforma provocará una reacción favorable de la inversión privada, especialmente la extranjera, convergente además con el interés nacional. Se asume, sin demostración o evidencia que vaya más allá de la argumentación doctrinaria general, de las ventajas de la competencia y del mercado, que será posible maximizar la explotación de los hidrocarburos, generar mayores ingresos para el gobierno y revertir la tendencia decreciente del excedente petrolero.

Ante el estancamiento crónico de la capacidad instalada de refinación y petroquímica y el reforzamiento del sesgo exportador de petróleo crudo, característico del sector petrolero mexicano durante las últimas décadas, el nuevo paradigma petrolero, así forjado, constituye un retorno al modelo de enclave primario exportador, ahora en el entorno de la globalización, soportado por la expectativa de que la inversión extranjera directa permita fortalecer el horizonte de explotación y extracción acelerada de los hidrocarburos.

En cambio, el modelo de reforma que el país requiere debería concentrarse en fortalecer y no en debilitar o acotar, la función del Estado en la conducción y rectoría del sector; pues abandonaría el sesgo exportador primario, dedicando los hidrocarburos prioritariamente, para privilegiar y garantizar la seguridad energética de la nación y así satisfacer las demandas nacionales. Para ambos objetivos, debe rectificarse la escasa atención prestada, realmente, a un vigoroso desarrollo de energías renovables, que signifique también la contribución de México al empeño global de combatir el cambio climático. La transición energética -imperativo global insoslayable en casi todas las economías del orbe-, es sin duda el más importante elemento ausente en la reforma, susceptible de hacer viable la transformación del sistema energético nacional en torno a una estrategia de desarrollo económico y social sustentable. Con estos principios se construiría otro modelo de organización y operación de la industria petrolera mexicana y también del resto del sector de energía. 